\title{
A study of dispersion in complex terrain under winter conditions using high-resolution mesoscale and Lagrangian particle models
}

\author{
J. L. Palau ${ }^{1}$, G. Pérez-Landa ${ }^{1}$, J. Meliáa ${ }^{2}$, D. Segarra ${ }^{2}$, and M. M. Millán ${ }^{1}$ \\ ${ }^{1}$ Fundación Centro de Estudios Ambientales del Mediterráneo (CEAM), València, Spain \\ ${ }^{2}$ Departamento de Termodinàmica, Facultat de Física, València, Spain
}

Received: 6 October 2005 - Published in Atmos. Chem. Phys. Discuss.: 22 November 2005

Revised: 7 February 2006 - Accepted: 7 February 2006 - Published: 4 April 2006

\begin{abstract}
A mesoscale model (MM5), a dispersive Langrangian particle model (FLEXPART), and intensive meteorological and COrrelation SPECtrometer (COSPEC) measurements from a field campaign are used to examine the advection and turbulent diffusion patterns associated with interactions and forcings between topography, synoptic atmospheric flows and thermally-driven circulations. This study describes the atmospheric dispersion of emissions from a power plant with a 343-m tall chimney, situated on very complex terrain in the North-East of Spain, under winter conditions. During the field campaign, the plume was transported with low transversal dispersion and deformed essentially due to the effect of mechanical turbulence. The main surface impacts appeared at long distances from the emission source (more than $30 \mathrm{~km}$ ). The results show that the coupled models (MM5 and FLEXPART) are able to predict the plume integral advection from the power plant on very complex terrain. Integral advection and turbulent dispersion are derived from the dispersive Lagrangian model output for three consecutive days so that a direct quantitative comparison has been made between the temporal evolution of the predicted threedimensional dispersive conditions and the COSPEC measurements. Comparison between experimental and simulated transversal dispersion shows an index of agreement between $80 \%$ and $90 \%$, within distance ranges from 6 to $33 \mathrm{~km}$ from the stack. Linked to the orographic features, the simulated plume impacts on the ground more than $30 \mathrm{~km}$ away from the stack, because of the lee waves simulated by MM5.
\end{abstract}

\section{Introduction}

Dispersion of pollutants emitted from tall chimneys has been widely studied since the beginning of the twentieth cen-

Correspondence to: J. L. Palau

(jlp@confluencia.biz) tury. The transport of air pollutants (mainly tracers and $\mathrm{SO}_{2}$ plumes) in stratified layers over land was documented in the US in the mid-to-late 1960s (Singer and Smith, 1966). Some of the available results were consolidated in the reports by Slade (1968) and ASME (1973) and reviewed by Pooler and Niemeyer (1971). For industrial stacks, the formation of stable plumes was considered a rare phenomenon resulting from the emission of hot effluents into a stable atmosphere (with shear, for a thin but wide, "fanning-type" plume, and without shear, for a thin and narrow, "ribbon-type" plume). The most significant aspects of this phenomenon were that the plumes became very thin, under essentially no vertical diffusion, and could be found at large distances from their sources after onenight's travel (Brown et al., 1972). It was also realised that the observed behaviour of the plume reflected the properties of the atmospheric layers in which it had become embedded.

These observations became more and more frequent in the early 1970s with the tracking of plumes from tall stacks. Passive remote sensing COrrelation SPECtrometer (COSPEC) measurement campaigns documented their travel distances to hundreds of $\mathrm{km}$ from the source (Millán and Chung, 1977; Millán, 1978b; Carras and Williams, 1981). They also documented that stratified plumes could form and/or persist during the day, whenever conditions were right (Uthe and Wilson, 1979; Portelli et al., 1982; Hoff and Gallant, 1985; Millán, 1987).

Passive remote sensing lidar measurements (measuring both mean values and turbulent components) have also been extensively used since the beginning of the 1970s to study tropospheric flows and the atmospheric dispersion of plumes emitted from point and area sources within the planetary boundary layer, PBL (Luhar and Young, 2002; Fast and Darby, 2004). Nevertheless, to the author's knowledge, available databases using lidar remote sensing technology and including simultaneous measurements of fumigations on the ground, are associated with field campaigns lasting only few days, e.g., the Nanticoke Shoreline Diffusion Experiment

Published by Copernicus GmbH on behalf of the European Geosciences Union. 
(Hoff et al., 1982); the Kwinana Coastal Fumigation Study (Sawford et al., 1998) and the Vertical Transport and Mixing Program, VTMX (Doran et al., 2002).

The availability of measurements aloft enables us to verify the patterns of advection and turbulent diffusion which govern atmospheric pollutant dynamics in complex topography areas (as a previous step to the analysis of the causeeffect relation between the emission source and the groundlevel concentration). In complex topography, availability of simultaneous measurements aloft and at ground level is a clear advantage because surface concentrations and plume pathways aloft are not necessarily correlated (essentially due to the vertical wind directional shear and to the heterogeneity of the physiographic thermodynamic properties of the ground). Moreover, ground-level pollutant concentrations typically present high spatial variabilities that are difficult to simulate because they result from non-stationary three-dimensional circulations and recirculations of pollutants driven by valleys, hills, mountains and any other topographic feature (Zaremba and Carroll, 1999).

At present, most simulated dispersion results are generally checked either against measurements of tracer-pollutant surface concentrations, with the dispersion analysis limited to the impact areas (Souto et al., 2001; Martín et al., 2001; Fast, 1995; Fast et al., 1995; Luhar, 2002); or occasionally, against instrumented airplane measurements taken during field campaigns lasting several days (Carroll and Baskett, 1979; Millán et al., 1992). In this latter case, the measurements recorded along the airplane pathway are difficult to compare with simulated concentrations due to the former's high temporal and spatial resolution ${ }^{1}$ (Eastman et al., 1995; Carvalho et al., 2002).

Complementing the previously published studies performed in the Iberian Peninsula with correlation spectrometer techniques (as e.g., Albizuri, 1985; Millán et al., 1987, 1991; Alonso et al., 1987, 1993; Salvador et al., 1999; Artiñano et al., 1993; Querol et al., 1999; Palau et al., 2001), this paper presents what is to our knowledge the first dispersive study using measurements aloft and on the ground simultaneously, together with numerical models resolving mesoscale forcings in the study area to reproduce the threedimensional wind and turbulent fields.

In this study, the mesoscale model MM5, the dispersive Langrangian particle model FLEXPART, and the intensive meteorological and COSPEC measurements obtained during one of the "Els Ports-Maestrat" field campaigns are used to examine the advection and turbulent diffusion patterns under typical winter conditions that are associated with interactions and forcings between topography, synoptic atmospheric flows and thermally-driven circulations on a midlatitude complex terrain. A unique aspect of this study is

\footnotetext{
${ }^{1}$ Simulated concentrations are generally hourly averaged (in time and space), while measurements taken with an airplane are quasi-instantaneously recorded along the plane pathway.
}

that integral advection and turbulent dispersion are derived from the dispersive Lagrangian model output for three consecutive days so that a direct quantitative comparison can be made between the temporal evolution of the predicted threedimensional dispersive conditions and the COSPEC measurements. Nearly all of the COSPEC measurements are employed. After the predicted dispersive conditions have been evaluated (analysing the integral advection of the plume aloft and the horizontal turbulent diffusion), we present the analysis of the ground impacts due to both meso and locally-driven flows, including the consequences of orographical effects on the simulated wind fields.

\section{2 "Els Ports-Maestrat" field campaigns: Els Ports database}

The Els Ports-Maestrat field campaign, sponsored by the Environment Department of the Valencia (Spain) regional government, has been conducted at the Southwestern border of the Ebro basin since November 1994. One of the main objectives of this field campaign is to monitor (aloft and on the ground) the $\mathrm{SO}_{2}$ plume emitted from the $343-\mathrm{m}$ tall stack of the Andorra Power Plant (APP) located at Teruel (Spain), Figs. 1 and 2. Another objective is to study the possible effects on the APP emissions on the Els Ports/Maestrat forest masses. Thus, the "Els Ports" database consists, on the one hand, of three independent (but related) meteorological and air quality databases that extend from the end of 1994 to the present (2005), and, on the other hand, of a fourth database, complementary but independent from the plume monitoring, generated from a parallel monitoring of the state of the vegetation in a network of selected plots within the study area.

The first database is constituted by a systematic tracking of the $\mathrm{SO}_{2}$-plume emitted from the APP (Teruel, Spain). Measurements are performed at different distances from the chimney (along the available road network, Figs. 2 and 1b) with the double aim of (1) monitoring the plume's atmospheric dispersion (advection+turbulent diffusion) and ground impacts over complex terrain under different meteorological conditions and (2) identifying (and quantifying) the recurrence of each dispersive scenario in this mid-latitude region. The set of plume field measurements is very extensive; at present, it includes more than 3236 experimental plumedistributions registered spatially during the 1994-2004 period (equally distributed during the four annual seasons).

The second and the third databases are sets of measurements obtained from the Regional Air Quality Network (measuring continuously air pollutants and meteorological parameters), and from ENDESA (the power generation company, owner of this power plant). The available meteorological data (wind direction, wind speed, temperature and shortwave radiation) are recorded electronically every $15 \mathrm{~min}$ at $10 \mathrm{~m}$ above the ground. Sensors are located on different sites in the area (Fig. 2), and they have different temporal coverage 


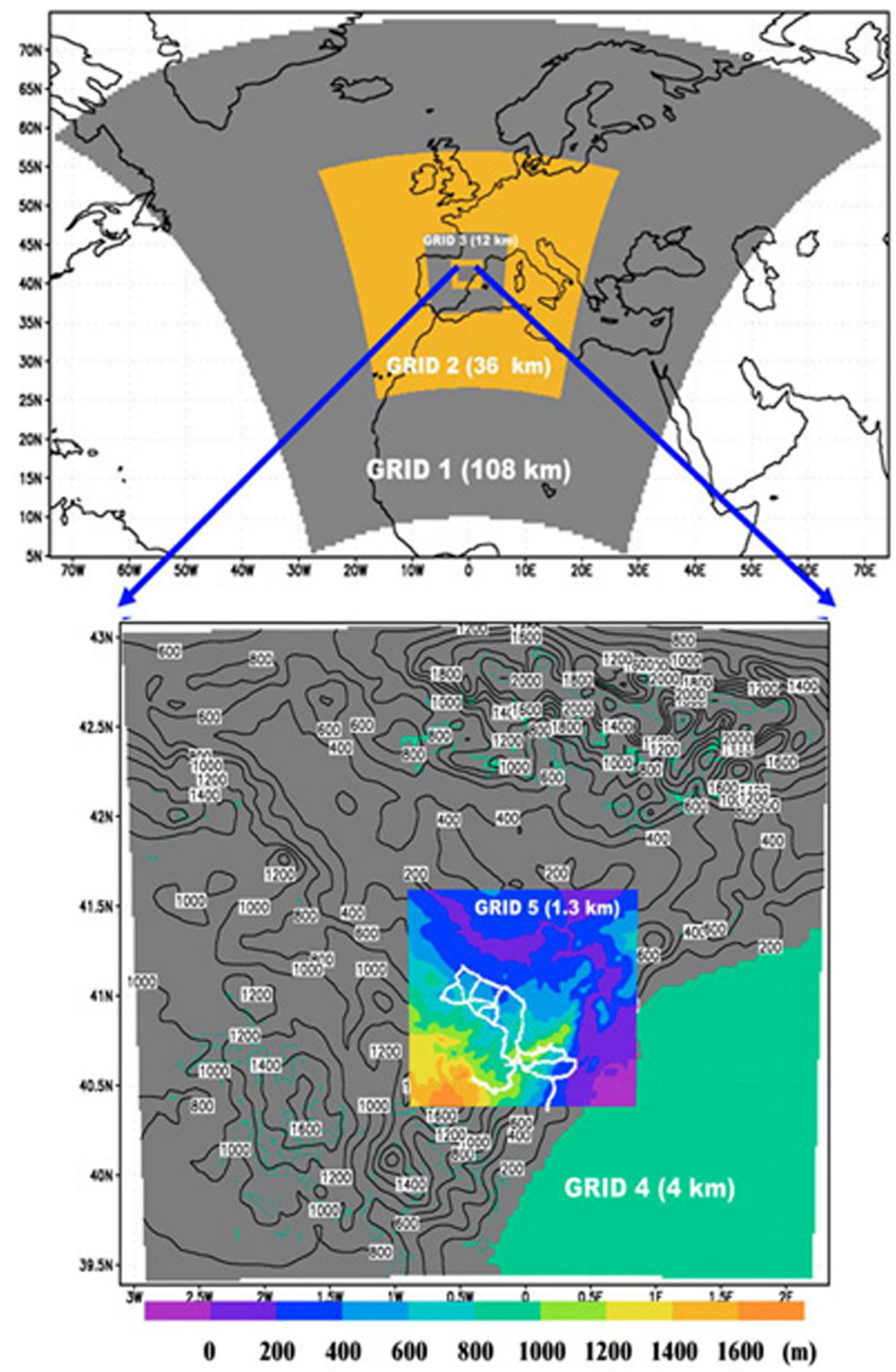

Fig. 1. Modelling configuration with the five grids of different resolution employed in the simulations centred over the Andorra power plant $\left(G_{1} 108 \mathrm{~km}, \mathrm{G}_{2} 36 \mathrm{~km}, \mathrm{G}_{3} 12 \mathrm{~km}, \mathrm{G}_{4} 4 \mathrm{~km} ; \mathrm{G}_{5} 1.3 \mathrm{~km}\right)$. Road network used by the mobile units (instrumented with a COSPEC) to take measurements around the power plant is also indicated in white in the fifth grid.

because they were installed at different times during the last decade. Besides, ENDESA has two more meteorological towers located near the power plant; one is $60 \mathrm{~m}$ in height and the other (Monagrega) is $10 \mathrm{~km}$ away.
The fourth database consists of two types of forested plots: plots with conifers and plots where lichen transplants were made. This last database is not used further in the study presented in this paper, although it played an important role when defining the field campaigns (Palau, 2003). 


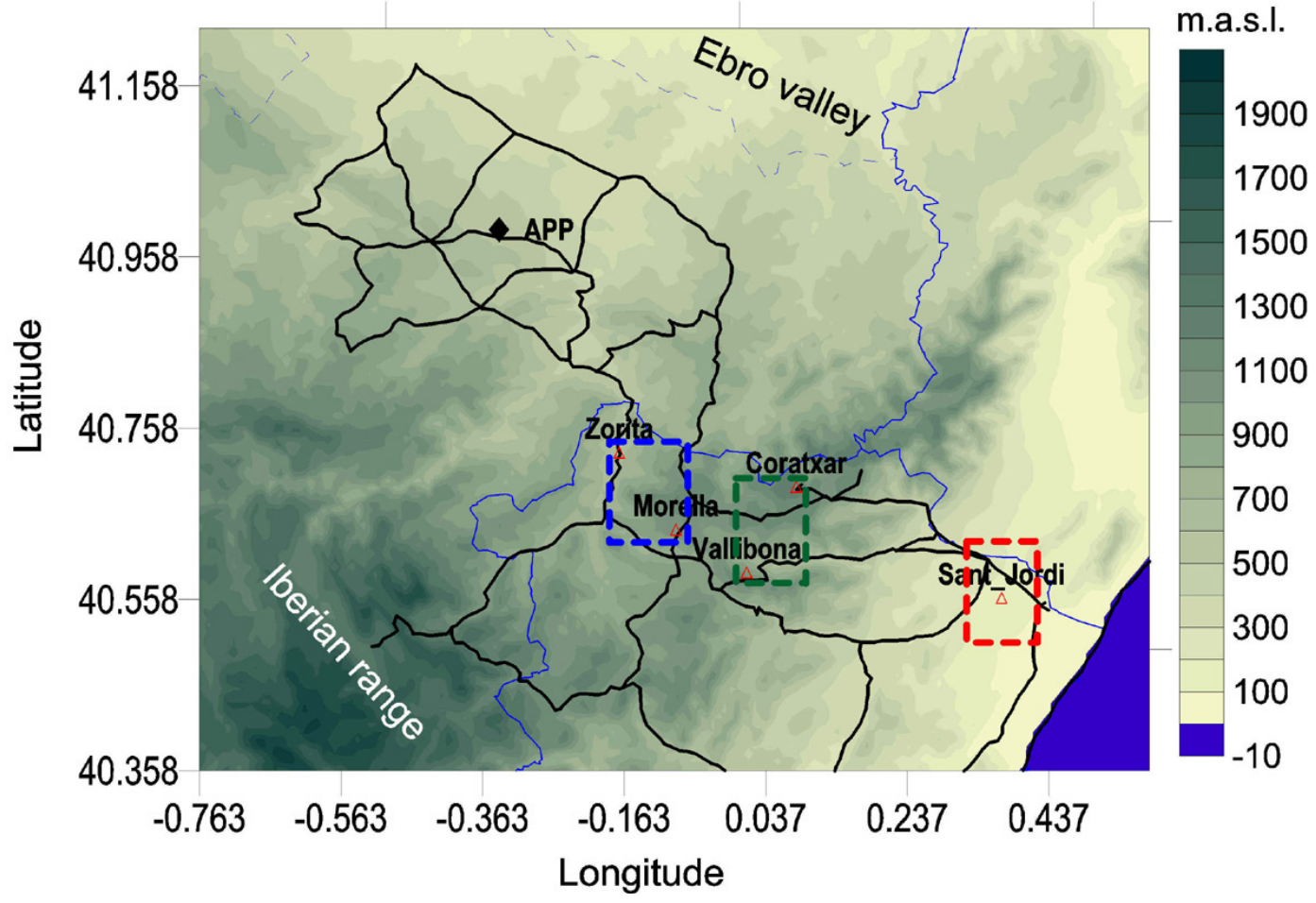

Fig. 2. Study area around the Andorra Power Plant (APP) in the North-East of the Iberian Peninsula, near the Mediterranean sea (bottom right corner). Blue lines indicate borders of three Spanish provinces. Black lines indicate the available road network around the APP. Locations of five air quality and meteorological stations are also indicated; an additional $60 \mathrm{~m}$-high meteorological tower is located beside the APP. Rectangles indicate the three different orographic areas where plume impacts on the ground were analysed by comparing the simulated results with measurements (area 1: blue color dashed square, area 2: green square and area 3: red square).

\section{Study area}

The Andorra Power Plant (APP) - ENDESA, 1050 MW with a 343-m-tall chimney, is located near the city of Andorra (Teruel), $\left(00^{\circ} 22^{\prime} 46^{\prime \prime} \mathrm{W} ; 40^{\circ} 59^{\prime} 54^{\prime \prime} \mathrm{N}\right), 87 \mathrm{~km}$ from the Spanish Mediterranean coast, in the Southwestern border of the Ebro basin $(605 \mathrm{~m}$ above sea level (m a.s.l.). The APP, licensed for construction in 1974, would nowadays be considered a medium-size installation, with three generators of $350 \mathrm{MW}$ each. Nevertheless, it uses large amounts of low-grade lignite with high sulphur content (from 12000 to 15000 tons/day, with 5-6\% sulphur content) (ENDESA, 1994), which translates into high $\mathrm{SO}_{2}$ emissions $\left(11.2 \mathrm{~g} / \mathrm{Nm}^{3}\right.$ in 1987).

The study area comprises three main basins (Fig. 2): the Mediterranean coast (East from the Power Plant), the Ebro valley (North from the Power Plant, running from NNW to ESE) and the Northeastern ridges of the Iberian Range (South and Southeast from the Power Plant).

The area includes the semi-arid plane of Calanda $(100 \mathrm{~km}$ inland from the coast, with a mean altitude of $600 \mathrm{~m}$ a.s.l.), some mountain ranges on the Northwestern side of the Iberian Range (Mediterranean forest with a mean altitude of 1000 to $1300 \mathrm{~m}$ a.s.l) and the coastal plain of Castellon (veg- etation characterised by irrigated crops). This coastal plain is delimited to the North, $7 \mathrm{~km}$ from the coast, by a mountain range of $780 \mathrm{~m}$ a.s.l. (with a very steep slope towards the coastal side).

Within this area, strong and extensive micro and mesoscale circulations develop, which are enhanced and driven by topography (Millán, 2002). Previous studies (Carroll and Baskett, 1979; Millán et al., 1992; Liu and Carroll, 1996; COST710, 1998; Kitada et al., 1998; Zaremba and Carroll, 1999) have emphasized how complex terrain drives micro-andmeso-scale secondary circulations. These, superimposed on the general flow (synoptic scale), drive the advection of momentum, energy, moisture and mass, within scales essentially different from those of turbulence (lower scale), which are the focus of "traditional" dispersion models. Secondary circulations are responsible for cumulus development (convective clouds) associated with mountain barriers (Huggins et al., 2005), leewaves perturbing general flow streamlines of the lower troposphere, etc. In this sense, some studies under Foehn conditions have already been performed on the North coast of the Iberian Peninsula (Gangoiti et al., 2002) using RAMS $^{2}$ model.

\footnotetext{
${ }^{2}$ RAMS: Regional Atmospheric Modeling System: http://www. atmet.com
} 
Dispersive patterns characteristic of the elevated plume emitted from the $343 \mathrm{~m}$-tall chimney are frequently the result of the interaction between these kinds of thermal and/or mechanical circulations and flows driven by larger spatial scales (synoptic scale), Palau (2003).

In wintertime (from October to March), previous results (Palau, 2003) showed that the synoptic conditions driving Northwest advections represent up to $57 \%$ of the field campaigns carried out during the 1995-2000 winter period (study performed from a total of 112 different campaign days during that period). This dispersive scenario is associated, from a synoptic point of view, with anticyclonic conditions over the Iberian Peninsula and Southeastern Europe; it is one of the two most representative dispersive conditions prevailing in the Northeast region of the Iberian Peninsula (mainly associated with neutral to stable atmospheric conditions). Under such winter meteorological conditions, with completely clear skies, temperatures around $0^{\circ} \mathrm{C}$ and moderate-to-strong Northwestern wind flows, the plume aloft is advected with very low transversal and vertical dispersion (ribbon-type integral advective conditions) and it is deformed (differential advection) only by mechanical turbulence leeward mountain ranges (Palau et al., 2004). Thus, the main plume impacts on the ground are located far away from the chimney (more than $30 \mathrm{~km}$ ), and generally within spatial areas on the ground that are in good agreement with the direction of the general wind flow aloft. Nevertheless, on occasion, intense fumigations near the chimney, i.e. within $30 \mathrm{~km}$, have been recorded in coincidence with either high wind-speed events (mechanical turbulence) or low wind speeds around noon under anticyclonic conditions (convective turbulence associated with insolation and dry surface conditions).

\section{Methodology}

\subsection{Experimental setup}

To monitor the plume transport and ground-level fumigation we took systematic remote-sensing measurements using a mobile unit equipped with a Correlation Spectrometer System - COSPEC - and a conventional $\mathrm{SO}_{2} \mathrm{UV}$ analyser, since this equipment makes it possible to record the distribution of the pollutant both aloft and on the ground (Newcomb and Millán, 1970).

The COSPEC is a passive remote sensor that uses the sunlight dispersed in the atmosphere as its radiation source. Its response is proportional to the integral of the $\mathrm{SO}_{2}$ concentration (throughout the optic path between infinity and the instrument telescope). The pulsed fluorescence analyser is used to measure the $\mathrm{SO}_{2}$ concentration over the roof of the vehicle.

The plume-tracking strategy consisted of making transects, as transversal as possible to the mean plume-transport direction, at different distances from the stack. Measure- ments were taken throughout the day to record any changes that might occur in the plume transport direction or in the dispersive conditions (Fig. A1).

To obtain the dispersive parameters implicitly contained in the experimental data, Pseudo-Lagrangian averages were carried out (Millán, 1978b). This average is made with the coordinates related to the centre of gravity of each profile; thus, meandering effects are not taken into account. This profile, averaged in time but not in space, shows the relative diffusion of the plume and keeps its morphologic features (Millán et al., 1976): bifurcation, directional shear effect, wind-speed shear effect (i.e., Kurtosis), etc. Further details in Appendix A.

Concerning the available ground-based meteorological and air quality information, data from five air quality stations and from one $60 \mathrm{~m}$-tall tower were available. The geographical description for each site is as follows (Fig. 2):

The Morella station is located at the top of a $1160 \mathrm{~m}$-high mountain, $50 \mathrm{~km}$ southeast of the Andorra power plant and $55 \mathrm{~km}$ inland from the Mediterranean coast. The Zorita station is located around $40 \mathrm{~km}$ from the power plant and at the bottom of a deep valley (the Bergantes valley). The Coratxar station is located $55 \mathrm{~km}$ southeast of the power plant and $42 \mathrm{~km}$ inland from the sea, at the top of a $1100 \mathrm{~m}$-high mountain. The Vallibona station, $60 \mathrm{~km}$ from the chimney, is located SE from the power plant at $666 \mathrm{~m}$ a.s.1. The Sant Jordi station is located on a coastal plain North of the city of Castellon, about $80 \mathrm{~km}$ from the power plant and about $20 \mathrm{~km}$ from the Mediterranean coast. The $60 \mathrm{~m}$-high meteorological tower, located at the power plant and near the chimney, measures wind speed and direction at $60 \mathrm{~m}$ above ground level (m a.g.l.) and temperature at $10 \mathrm{~m}$ a.g.l.

Although the geographical distribution of the air quaility stations is biased towards the Southeast of the power plant (Fig. 2), this feature is not relevant to the present study because of the steady Northwest wind advection registered throughout the campaign.

There is no meteorological information aloft within the study area; thus, the comparison between the simulated wind fields aloft and those occurring during the campaign days was performed using measurements of the plume aloft (obtained with the COSPEC) as a tracer of opportunity of the wind flow at the mean plume transport height.

Total emission data available are monthly averages of the emission flow. Moreover, from the $60 \mathrm{~m}$-high tower, meteorological measurements were recorded at 10 and $60 \mathrm{~m}$ a.g.l. every $15 \mathrm{~min}$.

\subsection{Model configuration}

We used a non-hydrostatic mesoscale meteorological model MM5, version 3.2 (Dudhia, 1993; Grell et al., 1995) coupled to a Lagrangian Particle Dispersion (LPD) Model FLEXPART, version 3.1 (Stohl, 1999; Stohl et al., 2005). 


\subsubsection{MM5 mesoscale meteorological model configuration}

The MM5 model used a nested-grid configuration with 5 domains $(100 \times 100$ grids spaced at $108,36,12,4$ and $1.3 \mathrm{~km}$, respectively) centred over the power plant (Fig. 1). The inner four domains are two-way interactive and are nested into the coarser domain, that is, run in 1-way mode. Thirty-nine sigma levels were configured, fifteen of them defined within the first $1500 \mathrm{~m}$ above ground level ( $\mathrm{m}$ a.g.l.).

The model predicts the three-dimensional wind components $u, v$ and $w$, the temperature, the humidity, the pressure perturbation and the associated turbulence parameters, as surface fluxes of heat, humidity and momentum. Multilayer Blackadar Planetary Boundary Layer (PBL) parameterization is employed to represent turbulent fluxes of heat, moisture and momentum (Zhang and Anthes, 1982). Boundary and initial conditions of atmospheric fields are derived from NCEP reanalysis data, available every $6 \mathrm{~h}$ at $2.5^{\circ}$ resolution (Kalnay et al., 1996). Four-dimensional data assimilation (Stauffer and Seaman, 1994) was applied to the coarser domain, nudging towards the gridded reanalysis fields. KainFritsch (1993) cumulus parameterisation was active in the three external domains.

Terrain data and properties like albedo, roughness and available soil moisture vary horizontally accordingly to the USGS (U.S. Geological Survey) topography and land use database, with $30^{\prime \prime}$ resolution.

\subsubsection{FLEXPART Lagrangian particle disperson (LPD) model configuration}

The FLEXPART-v3.1 model (Stohl, 1999) was fed by the MM5 meteorological outputs, using a grid configuration with one domain, which coincided with MM5 grid 5 (i.e., $100 \times 100$ grids spaced at $1.3 \mathrm{~km}$ and centred over the power plant).

The FLEXPART-LPD model takes into account wind velocity variances and Langrangian autocorrelations. The spread of the pollutant is simulated by the Langevin equation derived by Thomson for inhomogeneous and Gaussian turbulence under non-stationary conditions (McNider et al., 1988). Lagrangian time scale is considered a function of the turbulent and stability conditions within the PBL. Turbulence statistics are obtained by using the Hanna scheme with some modifications taken from Ryall and Maryon for convective conditions (Stohl and Seibert, 2001). The Gaussian turbulence assumption is not strictly valid under convective conditions when the vertical velocity distribution is skewed. However, the differences between a Markov process that includes wind velocity covariances and one that neglects them are likely to be very small as Uliasz (1994) showed when evaluating different LPD model simplifications over mesoscale and regional areas. The FLEXPART model incorporates a density correction term for Gaussian turbulence which takes into account the density decrease with height within the PBL (Stohl and Thomson, 1999).

The autocorrelation coefficient is assumed to be an exponential function that depends on the Lagrangian time scale. The time step used to move particles in the Markov chain model has to be variable in inhomogeneous turbulence and depends on the Lagrangian time scale (Uliasz, 1994). Wellmixed profiles can be obtained as long as the timestep is small enough to resolve the small-scale turbulence in the vicinity of the boundaries (Hurley and Physick, 1991).

Independently of the Langevin equation implemented within LPD models, to simulate dispersion from punctual anthropogenic point sources it is necessary to consider the emission heights of the Lagrangian particles.

A priori, from the available emission factors there is a large uncertainty when estimating the plume rise; thus we checked the eventual effect of plume-rise on the results obtained from the FLEXPART model by performing three independent dispersion simulations on the basis of three different plume-rise schemes:

- Releasing Lagrangian particles at variable heights, estimated each hour using Briggs' plume-rise equations for hot plumes (Briggs, 1975).

- Releasing Lagrangian particles at a constant height of $700 \mathrm{~m}$ a.g.l. (constant plume-rise of $357 \mathrm{~m}$ a.g.l.)

- Releasing Lagrangian particles at a constant height of $450 \mathrm{~m}$ a.g.l. (constant plume-rise of $107 \mathrm{~m}$ a.g.l.)

It is important to note that these last two constant values are based on visual estimations of the plume-rise behaviour during the three-day campaign; they are considered to be the maximum and minimum plume-rise values observed at different times of day during those three days. When using the Briggs' plume-rise equations, quantitative analysis of the evolution of the simulated PBL and the height of the first inversion aloft allows us to set limits to the plume rise.

In our simulations, we treated the buoyant plume of the Andorra power plant by releasing $2 \times 10^{6}$ particles at different effective stack heights. The particles were randomly released and linearly distributed within a $0.1 \times 0.1 \times 0.01 \mathrm{~km}$ volume over 95 -h period (from the beginning of the four-day simulation to the end).

From these dispersion simulations we obtain a time series of the three-dimensional distribution of Lagrangian particles (each one representing a specific volumetric concentration of pollutant).

\subsection{Model validation}

A wide variety of intercomparison procedures between experimental and simulated air-quality results have been found to be useful (Fox, 1981; Willmott, 1981; Weil et al., 1992; Seaman, 2000). These procedures, strongly determined by 
the number of available experimental data (data with a significant spatial-temporal resolution), generally focus on the intercomparison of deviations in maximum values, first-order statistical momentum, frequency distribution of concentration values, etc. (Carvalho et al., 2002; Fast et al., 1995; Uliasz, 1994; CityDelta web-page).

In our particular case, on one hand, the available data from the air quality network in the region have a good temporal resolution but a coarse spatial resolution. On the other hand, although with a much coarser temporal resolution, "Els Ports" database has also an extensive field campaigns covering the whole study area with a very good spatial distribution.

The availability of surface information from the Air Quality Network, and both surface and systematic tracking of the power plant plume aloft, allows a detailed validation of the skills of the aforementioned models (MM5+FLEXPART) in the simulation of the pollutants behaviour. Thus, the ability of the coupled models to simulate the two main physical processes driving air pollutant dispersion ${ }^{3}$ (advection and turbulent dispersion) can be evaluated.

\subsubsection{Direct comparison between plume tracking and model results}

Using the plume transport direction aloft as a tracer of opportunity of the wind field at the mean plume transport height, it is possible to make a direct comparison between the simulated dispersive conditions with the measurements of the plume aloft. Thus, two different but complementary physical processes can be analysed: (a) the integral-transport of the plume aloft, and (b) the turbulent dispersion (differential transport and turbulent diffusion) of the plume aloft. Additionally, simultaneous measurements of $\mathrm{SO}_{2}$ concentration at surface level during the plume tracking, allows the comparison between measured and simulated plume impact areas on the ground.

\subsubsection{Comparison of the simulated and measured transver- sal dispersion}

Obtaining typical horizontal deviations of the plume distribution aloft from the available experimental records has already been described in the literature (Millán et al., 1976; Millán, 1978b); nevertheless, details of the modified PseudoLagrangian method used in this study can be found in Appendix A. In this study, it is important to remark that, following this procedure and from the experimental measurements of the $\mathrm{SO}_{2}$ distribution aloft, mean values of transversal plume dispersion are obtained at different distances from the emission point and during a determinate temporal period.

\footnotetext{
${ }^{3}$ Following the terminology by Moran (2000). Within this paper, advection is considered the sum of integral transport and differential transport. Turbulent dispersion is considered as differential transport plus turbulent diffusion.
}
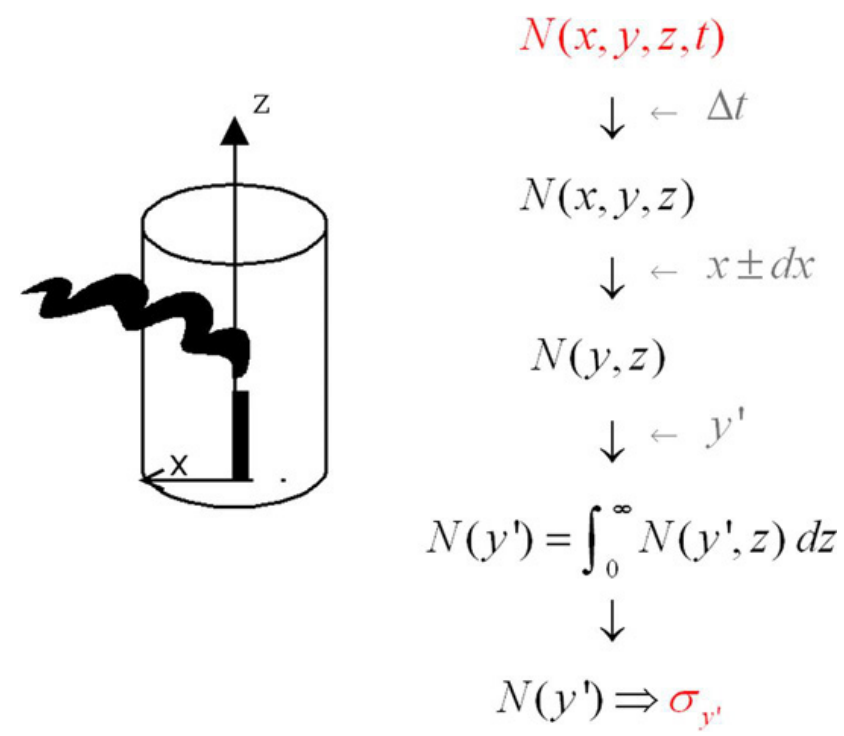

Fig. 3. Schematical representation of the procedure for estimating simulated transversal dispersion for fixed time periods and distances. It shows the process for reducing a three-dimensional distribution of Lagrangian particles, $N(x, y, z)$ during a time interval $\Delta t$, to a bi-dimensional distribution, $N(y, z)$, at a fixed distance from the point source, $x \pm d x$. Finally, the standard deviation of $N(y, z)$ is calculated as the vertical integration of the bi-dimensional Lagrangian distribution.

The procedure for estimating simulated transversal dispersion for fixed time periods and distances, Fig. 3, consists of reducing the three-dimensional distribution of Lagrangian particles to a bi-dimensional distribution (adding all the particles vertically) contained within a plane that is normal to the direction determined by the centre of gravity of the simulated particles during the fixed temporal period (the "simulated effective plane", Fig. A2). Moreover, the distance to the source completely determines that effective plane (that distance is fixed by the distance between the experimental effective plane and the chimney; further details in Appendix A).

\subsubsection{Comparison of spatial biases between measured and simulated ground-level $\mathrm{SO}_{2}$ concentrations}

The spatial density of the Air Quality Network is not enough to perform a detailed evaluation of the simulated groundimpact areas. However, availability of continous $\mathrm{SO}_{2}$ concentration measurements at the five sites, allowed the quantification of spatial biases between the measurements within the study area and the simulated ground-concentration field during the whole period considered. Thus, it is possible to evaluate the performance of the model simulating groundlevel concentrations during the different turbulent regimes implemented in the meteorological model. 


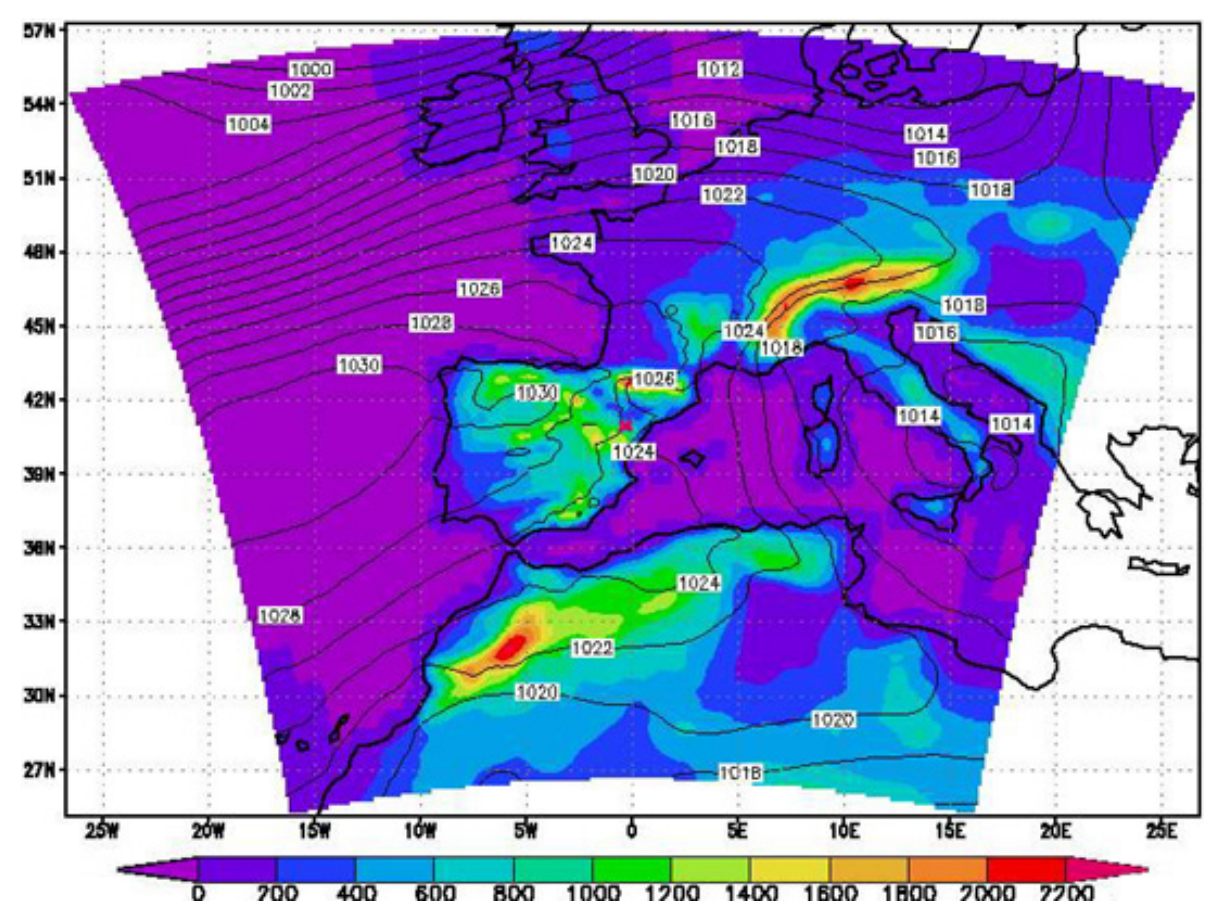

Fig. 4. Synoptic chart (grid 2) at 18:00 GMT on 28 November 2001. Typical anticyclonic conditions prevailed during the experimental campaign. Cross-isobaric flows advected the plume aloft towards the SE of the power plant (red cross at the North-East of the Iberian Peninsula).

\section{26-28 November case study}

The campaign of 26-28 November was selected as representative of the most recurrent winter scenarios in the area (winter Northwest advection, Appendix B); Palau, 2003. The analysis of synoptic conditions using NCEP Reanalysis data (Kalnay et al., 1996) and the meteorological datasets available in the region (not shown), confirm that typical winter conditions prevailed during the experimental campaign. On these days, meteorological situation within the study area was driven synoptically by three main pressure systems: an Atlantic anticyclone extending over the Iberian Peninsula, a Low located over the North of the British Isles and another low pressure system located on the Western Mediterranan Sea. This synoptic configuration (Fig. 4) drove crossisobaric flows, advecting the plume aloft towards the SE of the power plant (almost parallel to the Ebro valley axis towards the Mediterranean Sea) and inhibiting the development of thermally-driven local circulations. The passing of a cold front between 26 and 27 November, diminished temperatures and brought heavy cloudiness over the study area. After the cold front, skies cleared and wind speed increased substantially.

Forty transects (or, as previously indicated in the "Experimental setup" section, simultaneous recordings of the spatial $\mathrm{SO}_{2}$ distribution aloft and on the ground) were performed at different distances from the stack during the three-day campaign. Measurements were taken during the day and are con- sidered representative of the dispersive conditions around the APP during the field campaign.

The mesometeorological simulation was initialized on 25 November to avoid spin-up effects on the simulated results for the first day of the campaign and was run for four days. Meteorological simulated fields were used to drive the LPD model simulations during the same period.

\section{Results and discussion}

Time series of vertical profiles of wind field (Fig. 5a) and temperature (Fig. 5b) at the stack location during the whole simulated period, show the main meteorological features described previously. The passing of a cold front between 26 and 27 November, can be identified by the wind speed increase, a decrease in temperature (Fig. 5b) and the wind direction turning towards the South (Fig. 5a) between the days 26 and 27 . The simulated time series for the wind field and potential temperature show the predicted meteorological conditions for the three different emission schemes implemented in the LPD model (constant heights of 450 and $700 \mathrm{~m}$, and variable heights following the modified Briggs'plume-rise equations for hot plumes - Briggs, 1975; as indicated by colour lines, Figs. 5a and b). With respect to the dynamic emission conditions (wind speed and direction) for each of the three emission schemes no major differences are detected between them (Figs. 5a and b). 

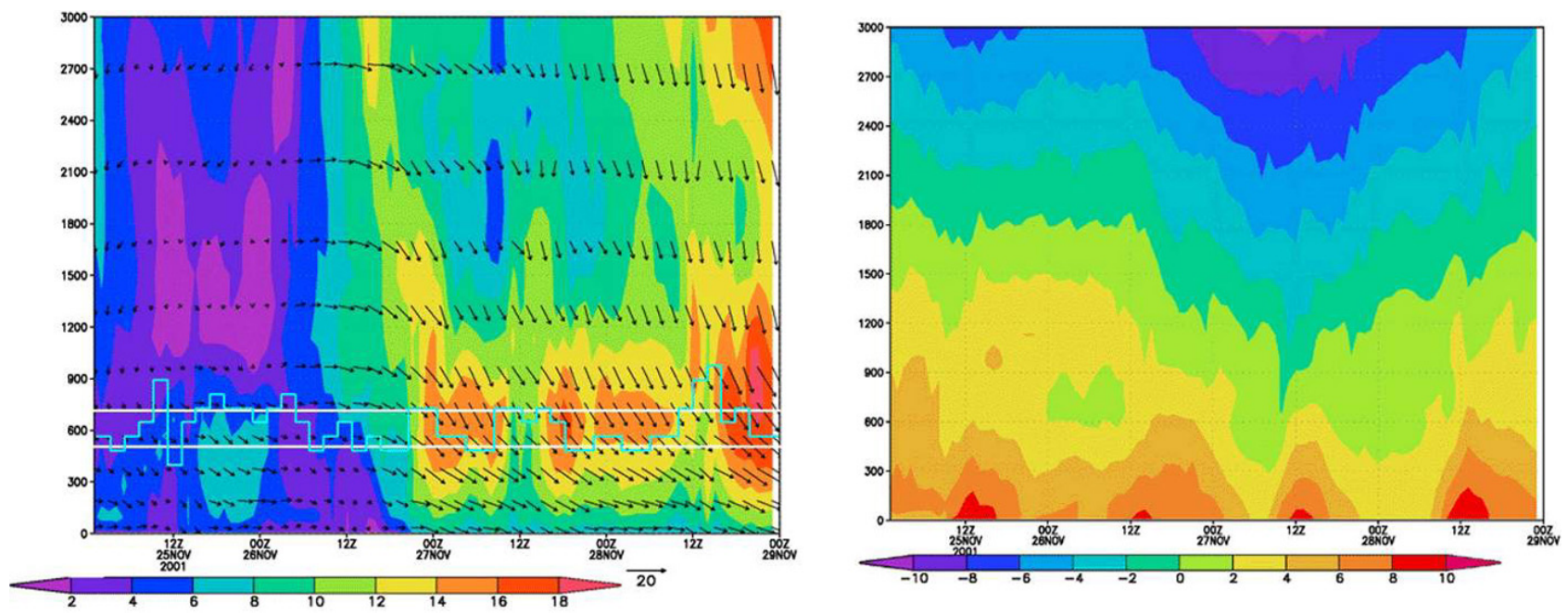

Fig. 5. Time series of the vertical profiles of wind field (left, a) and potential temperature (right, b) at APP site showing the meteorological conditions for the three different emission schemes implemented in the LPD model (constant heights of 450 and $700 \mathrm{~m}$, and variable heights following Briggs' modified plume-rise equations for hot plumes; as indicated by coloured lines in panel a).

On the power plant site, the simulated PBL has a height of 700-to-800 m a.g.l. on the 25th, 26th and 29th of November (not shown). On the 27th, after the cold airmass inflow and the wind speed increase, PBL ranges between 900 and $1200 \mathrm{~m}$ a.g.l. Besides, during the four simulated days, the simulated PBL is characterised by a surface layer in a muffled mechanical turbulence regime during the nocturnal hours (second category of the Blackadar parameterization implemented within MM5) with a PBL in a non-local free convection regime (fourth Blackadar category) only for two-to-five hours around noon (when incoming short-wave radiation is higher).

\subsection{Plume tracking versus model results}

As representative of the results obtained from the three emission schemes implemented in the LPD-model simulations, in this section we only present figures from the simulation performing the constant $700 \mathrm{~m}$-high emission scheme. Comparison between the measured plume dynamical behaviour throughout the day and the simulation is presented at different instants during the day, corresponding to the different dispersive conditions identified: (a) During the early morning and afternoon, measurements correspond to the nocturnal drainage flow where synoptic flows drive the plume dynamics and local mechanical turbulence governs the differential advection and diffusion (stirring and mixing) of the plume aloft but without major ground fumigations on the plane areas near the chimney; (b) during the rest of the day, until the afternoon, thermal mesoscale circulations (convection) affect the plume dynamics favoring plume fumigations near the chimney.

\subsubsection{Day: 26 November 2001}

For the first campaign day (the second simulated day), two instants are shown (Figs. 6a and b) as representative of the dispersive conditions throughout the day. The first corresponds to midday and the second to five hours later (late afternoon).

Experimental measurements show the plume aloft being advected eastward from the power plant during the whole day. This is mostly captured by the simulation, although a small deviation towards the South can be observed in the late afternoon (Figs. $6 \mathrm{c}$ and d). At noon, $\mathrm{SO}_{2}$-ground level concentrations were measured South of the mean plume transport direction aloft (along a mountainous barrier, $45 \mathrm{~km}$ from the chimney). Thus, from the integral-transport point of view, on this first campaign day, westerly winds prevailed according to both the simulation (Figs. 6c and d) and the measurements (Figs. 6a and b) of the the plume aloft.

The main simulated $\mathrm{SO}_{2}$ ground-level concentrations are spatially well correlated with the mean plume transport direction aloft (Figs. 6a, b, c, d, e and f). The highest $\mathrm{SO}_{2}$ ground impacts are located leeward of mountain barriers and at distances from the power plant ranging between 30 and $50 \mathrm{~km}$. The lowest $\mathrm{SO}_{2}$ ground impacts are also simulated and measured at shorter distances from the chimney, coinciding with periods with high short-wave radiation (associated with the free convection scheme performed by the MM5).

\subsubsection{Day: 27 November 2001}

To present the dispersive conditions for this second campaign day, we have selected three different instants during the day: in the morning, at noon, and in the late afternoon (Figs. 7a, b and 8a). On this day, simulated and observed 

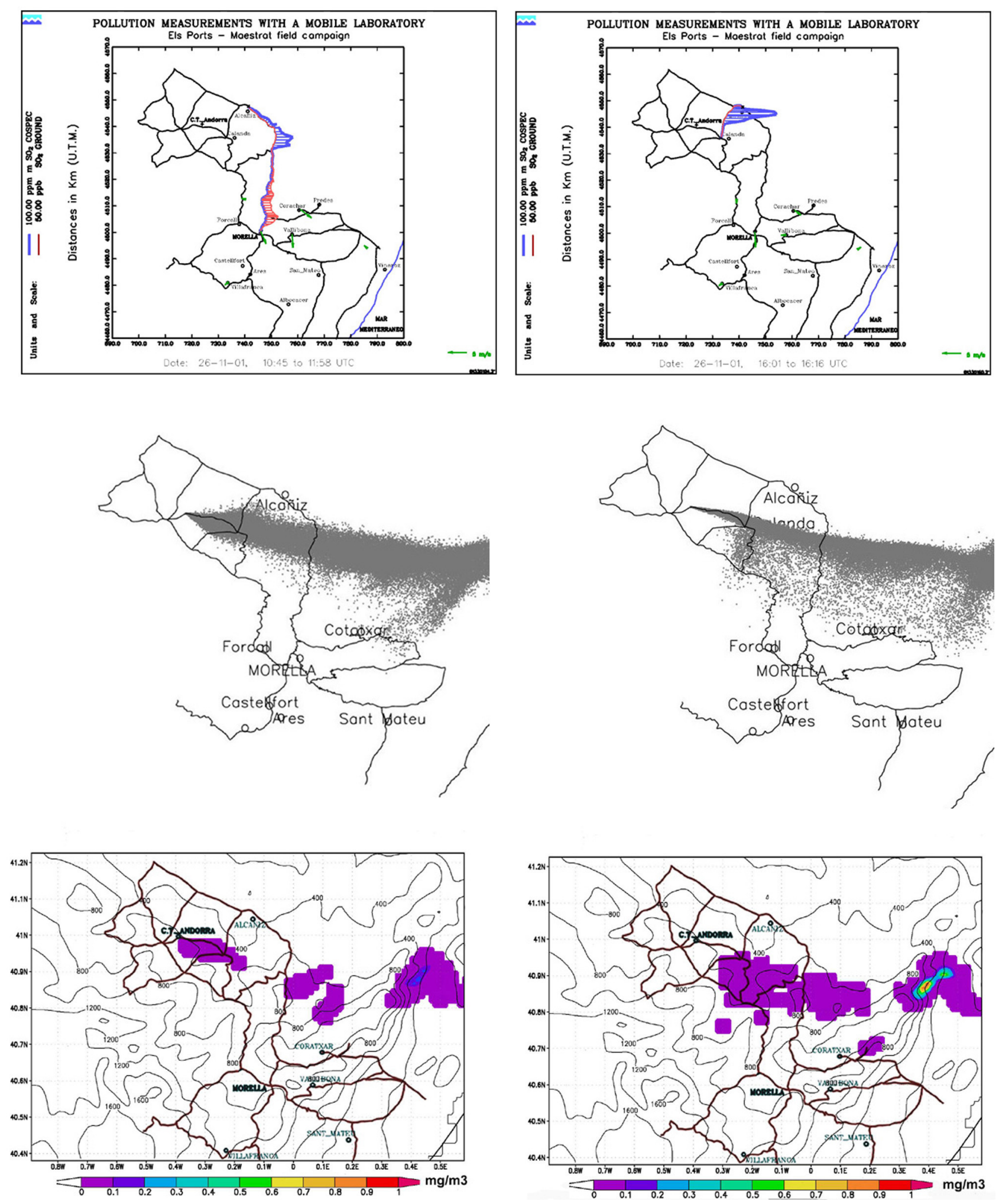

Fig. 6. First campaign day (26 November 2001). Top (a, b): COSPEC measurements of both the plume aloft (blue line) and its simultaneous impacts on the ground (red line); (a: 10:45-11:58 GMT; b: 16:01-16:16 GMT). Middle (c, d): Simulated Lagrangian distribution at 11:00 GMT (left) and 16:00 GMT (right). Bottom (e, f): Simulated $\mathrm{SO}_{2}$ concentrations on the ground at 11:00 GMT (left) and 16:00 GMT (right). 

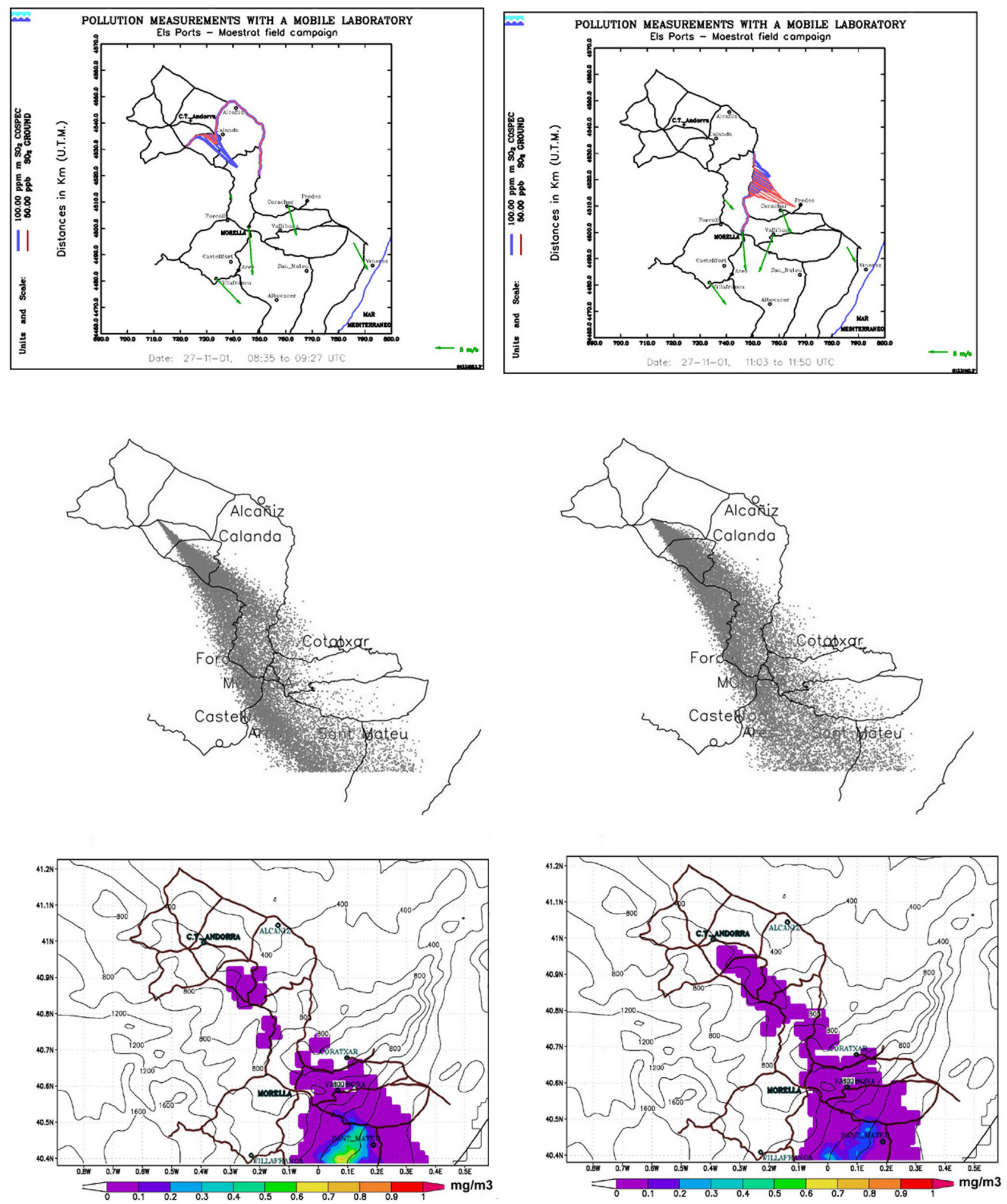

Fig. 7. Second campaign day (27 November 2001). Top (a, b): COSPEC measurements of both the plume aloft (blue line) and its simultaneous impacts on the ground (red line); (a: 08:35-09:27 GMT; b: 11:03-11:50 GMT). Middle (c, d): Simulated Lagrangian distribution at 10:00 GMT (left) and 11:00 GMT (right). Bottom (e, f): Simulated $\mathrm{SO}_{2}$ concentrations on the ground at 10:00 GMT (left) and 11:00 GMT (right). 

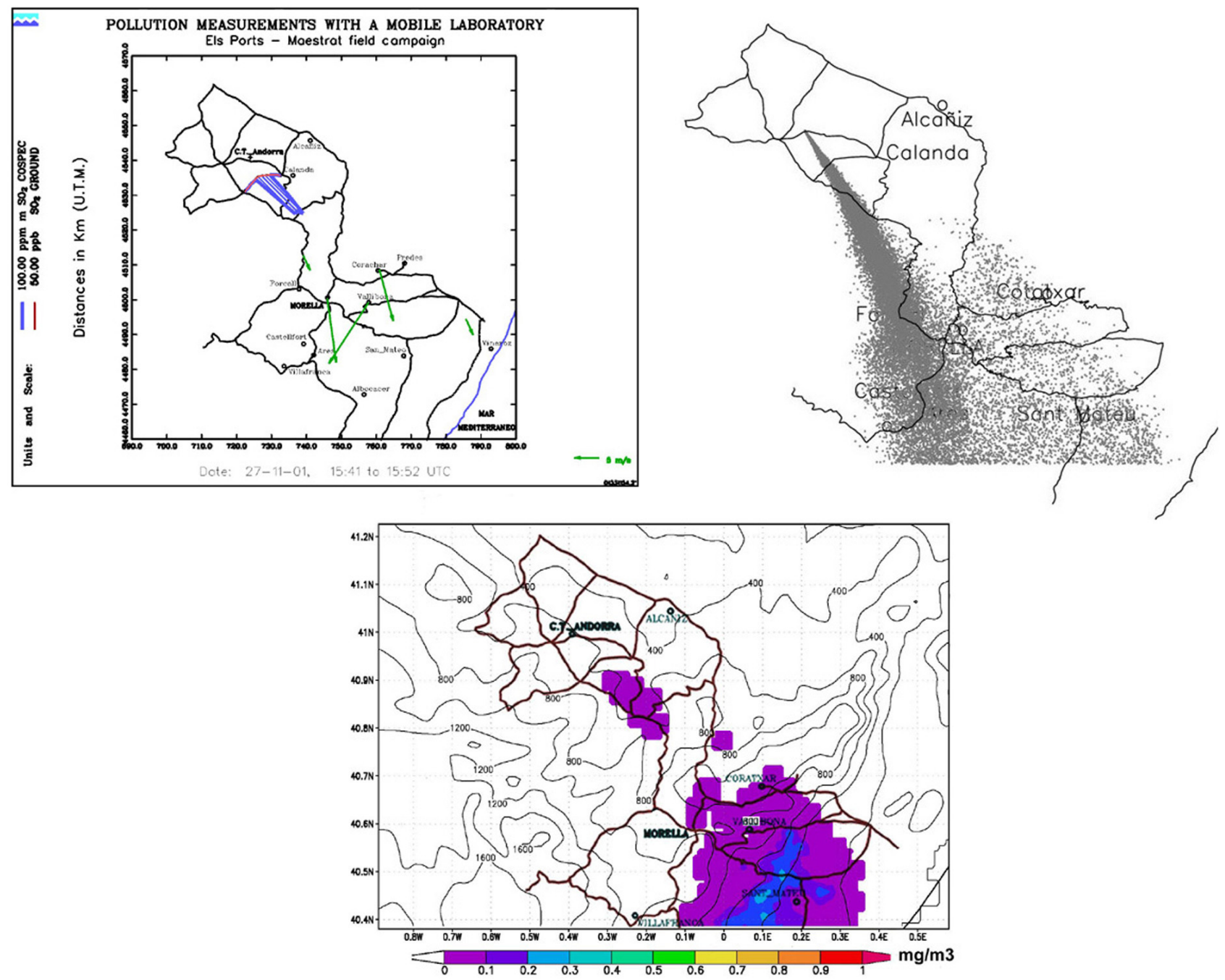

Fig. 8. Second campaign day (27 November 2001). Top-left (a): COSPEC measurements (15:41-15:52 GMT) of both the plume aloft (blue line) and its simultaneous impacts on the ground (red line). Top-right and bottom (b, c): Simulated Lagrangian distribution (bottom) and $\mathrm{SO}_{2}$ concentrations on the ground (right) at 16:00 GMT.

plume aloft is advected southeastward from the power plant during the entire day. Thus, from the integral-transport point of view, after the cold front passed, both the simulation and the experimentally-measured plume transport direction aloft changed towards the Southeast. During the afternoon, as a consequence of the wind speed increase at the plume transport height, the plume became thinner. A slight decrease in the transversal dispersion was observed due to wind speed increase during the afternoon (Figs. 6, 7 and 8, Table 1). The direction of the simulated plume seems to be slightly biased towards the South at 11:00 GMT (Figs. 7b and d) and at 12:00 GMT (Figs. 8a and b).

The measured $\mathrm{SO}_{2}$ ground impacts were light at short distances from the chimney in the morning, they increased around noon, and they began to decrease again during the afternoon. During this second campaign day, Figs. 7 and 8, the simulations also follow the experimentally recorded plume impacts on the ground. On the one hand, the highest impacts are simulated leeward of the mountain barriers and, on the other hand, the impacts close to the chimney are mainly simulated during the periods of time associated to the strongest convective activity. Changing the convective scheme used by the MM5 model within the PBL produces a reduction in the number of impacts on the ground near the chimney during the afternoon (compare Figs. $7 \mathrm{f}$ and $8 \mathrm{c}$ ).

Under these dispersive conditions, the simulated plume "footprint" (ground-level $\mathrm{SO}_{2}$ concentration) gives a good sense of the preferred plume advection aloft.

\subsubsection{Day: 28 November 2001}

As the previous day, throughout this third campaign day the plume aloft continued to advect southeastward from the 
Table 1. Experimental and simulated horizontal turbulent diffusion. Simulated values correspond to the three different emission schemes performed (constant heights: 450 and $700 \mathrm{~m}$ a.g.l., and Briggs' plume-rise scheme).

\begin{tabular}{cccrrrrr}
\hline $\begin{array}{c}\text { Day/ } \\
\text { Month }\end{array}$ & $\begin{array}{r}\text { Hour } \\
\text { Begin. }\end{array}$ & $\begin{array}{r}\text { Hour } \\
\text { End. }\end{array}$ & $\begin{array}{r}\text { Distance } \\
(\mathrm{km})\end{array}$ & $\begin{array}{r}\text { Experimental } \\
\text { Dispersion } \\
(\mathrm{km})\end{array}$ & $\begin{array}{r}\text { Simulated } \\
\text { dispersion } \\
\text { Briggs }(\mathrm{km})\end{array}$ & $\begin{array}{r}\text { Simulated } \\
\text { dispersion } \\
700 \mathrm{~m}(\mathrm{~km})\end{array}$ & $\begin{array}{r}\text { Simulated } \\
\text { dispersion } \\
450 \mathrm{~m}(\mathrm{~km})\end{array}$ \\
\hline 26 Nov & $10: 45$ & $11: 58$ & 26.68 & 3.03 & 1.70 & 1.33 & 3.18 \\
26 Nov & $13: 21$ & $14: 12$ & 20.57 & 1.14 & 1.64 & 1.40 & 1.29 \\
26 Nov & $15: 12$ & $15: 35$ & 15.79 & 2.49 & 1.59 & 1.05 & 1.75 \\
26 Nov & $16: 01$ & $16: 16$ & 12.33 & 1.02 & 0.55 & 0.90 & 2.01 \\
27 July & $08: 35$ & $09: 45$ & 8.04 & 0.94 & 0.40 & 0.25 & 0.34 \\
27 July & $09: 45$ & $10: 25$ & 13.02 & 1.69 & 1.22 & 0.50 & 1.03 \\
27 July & $11: 03$ & $13: 15$ & 32.78 & 2.45 & 2.19 & 1.63 & 2.14 \\
27 July & $14: 23$ & $15: 04$ & 6.87 & 0.58 & 0.76 & 0.84 & 0.73 \\
27 July & $15: 06$ & $15: 40$ & 14.99 & 1.05 & 1.74 & 1.85 & 1.90 \\
27 July & $15: 41$ & $16: 09$ & 6.40 & 0.86 & 0.50 & 0.69 & 0.81 \\
28 Nov & $08: 17$ & $09: 54$ & 19.84 & 1.00 & 0.83 & 0.56 & 0.74 \\
28 Nov & $09: 55$ & $11: 00$ & 6.18 & 0.85 & 0.00 & 0.00 & 0.50 \\
28 Nov & $11: 01$ & $11: 56$ & 7.41 & 1.54 & 0.84 & 0.50 & 0.73 \\
28 Nov & $11: 57$ & $13: 09$ & 6.33 & 1.13 & 1.01 & 0.93 & 0.84 \\
28 Nov & $14: 16$ & $14: 44$ & 6.31 & 0.93 & 0.50 & 0.49 & 0.87 \\
\hline
\end{tabular}

power plant. Thus, from the integral-transport point of view, both the simulation and the experimentally-measured plume transport direction aloft remain towards the Southeast. Temporal evolution of the simulated integral transport aloft, (Figs. 9c, d; 10c, d and 11b), shows that the model present very good skills, capturing the observed plume horizontal meandering.

In the early morning of the third campaign day, Fig. 9a, there are no measured impacts over the areas closest to the chimney, and the simulation only shows impacts leeward of mountain barriers 40 -to- $50 \mathrm{~km}$ from the power plant (there are no available mobile unit measurements in these areas during this period).

As on the previous day, around noon (Figs. 9b, d, f and Figs. 10a, c, e), the convective activity causes strong impacts on the ground near the power plant (as the experimental measurements show, Figs. 9b and 10a) and these are wellsimulated by the LPD model (Figs. 9f and 10e). Around 13:00 GMT, the impacts close to the chimney cease (experimentally documented, Fig. 10b); around the same time of day, the LPD model performed a progressive reduction of impacts near the point source (Fig. 10f).

During the afternoon (14:45 to 15:40 GMT), the mobil unit recorded a channelization of the plume along the Bergantes valley (southeast from the chimney), with $\mathrm{SO}_{2}$ ground-level concentrations along the whole valley. In agreement with these measurements, simulated $\mathrm{SO}_{2}$ impacts on the ground are recorded along the whole Bergantes valley (Southeast from the chimney) as a result of a topographically channelized simulated plume (Figs. 11a and c). In addition, the simulated strong $\mathrm{SO}_{2}$ ground impacts leeward of the mountains still remain.

\subsection{Horizontal turbulent diffusion}

Under the aforesaid dispersive scenario (synoptic Northwest winter advection) a good correlation between experimental and simulated transversal dispersion was obtained within a spatial area ranging between 6 and $33 \mathrm{~km}$ (Fig. 12 and Table 1).

Results show that the LPD model systematically underestimates transversal dispersion. Independent of the emission scheme performed, fittings between experimental and simulated transversal dispersion values have slopes lower than one (Fig. 12, Tables 1 and 2). Nevertheless, better results are obtained when using the Briggs' plume-rise scheme and the constant $450 \mathrm{~m}$-height scheme (both schemes have excellent statistical significance ${ }^{4}$ for the slope). From the 26th, these two emission schemes (Briggs and 450 m-height) present almost the same advective conditions all the time, which is not the case for the $700 \mathrm{~m}$-height scheme (Fig. 5a). Larger differences between the estimated plume rise obtained from the Briggs' scheme and the $450 \mathrm{~m}$-height scheme occur when very little vertical windspeed shear is simulated. On the contrary, when major vertical windspeed shear is simulated (with important differences between the $450 \mathrm{~m}$ and $700 \mathrm{~m}$ heights) Briggs' plume-rise is estimated around the $450 \mathrm{~m}$-height.

Mean square errors (MSE) obtained from the linear fittings are lower than one kilometre, of the order of the available measurement spatial resolution (Table 2). The adimensional index of agreement (IoA), Willmott (1981), is higher than

\footnotetext{
${ }^{4}$ General criteria is: $p$-value $\leq 0.001 \quad(* * *$, excellent significance); -value $\leq 0.01(* *$, good significance); $p$-value $\leq 0.05(*$, significant); $\mathrm{p}$-value $>0.05$ ( $\bullet$, no significance).
} 
Table 2. Statistical skills for the horizontal dispersion values simulated with the three different emission schemes. $m$ : fitting slope; $b$ : ordinate [km]; SE: Standard Error; MSE: Mean Squared Error; MSEu: Unsystematic Mean Squared Error; MSEs: Systematic Mean Squared Error; MSEa: Additive Mean Squared Error: MSEp: Proportional Mean Squared Error; MSEi: Interdependence Mean Squared Error; d: Index of Agreement. "Rs" indicate "Root" for every statistic.

\begin{tabular}{lcccccc}
\hline & $m$ & $b[\mathrm{~km}]$ & $\mathrm{SE}(m)$ & $\mathrm{SE}(b)[\mathrm{km}]$ & $\mathrm{p}$-value $(m)$ & $\mathrm{p}$-value $(b)$ \\
\hline $450 \mathrm{~m}$ & 0.81 & 0.13 & 0.20 & 0.30 & 0.001 & 0.667 \\
$700 \mathrm{~m}$ & 0.31 & 0.43 & 0.18 & 0.28 & 0.108 & 0.141 \\
BRIGGS & 0.60 & 0.20 & 0.17 & 0.26 & 0.003 & 0.468 \\
\hline & RMSE $[\mathrm{km}]$ & RMSEu & RMSEs & RMSEa & RMSEp & RMSEi \\
\hline $450 \mathrm{~m}$ & 0.53 & 0.49 & 0.18 & 0.13 & 0.29 & -0.26 \\
$700 \mathrm{~m}$ & 0.84 & 0.45 & 0.71 & 0.43 & 1.07 & -0.91 \\
BRIGGS & 0.62 & 0.43 & 0.44 & 0.20 & 0.61 & -0.46 \\
\hline & MSEu/MSE & MSEs/MSE & MSEa/MSE & MSEp/MSE & MSEi/MSE & $\mathrm{d}$ \\
\hline 450 m & 0.88 & 0.12 & 0.06 & 0.30 & 0.25 & 0.94 \\
700 m & 0.29 & 0.71 & 0.27 & 1.62 & 1.17 & 0.80 \\
BRIGGS & 0.48 & 0.52 & 0.10 & 0.98 & 0.56 & 0.90 \\
\hline
\end{tabular}

$90 \%$ for the simulations using the Briggs' and $450 \mathrm{~m}$-height schemes, while it is $80 \%$ for the simulation using a constant $700 \mathrm{~m}$-height scheme.

A dependence is detected between the emission scheme performed and the contribution of systematic and unsystematic errors to the total MSE. Whereas with the $450 \mathrm{~m}-$ height scheme a systematic contribution of $12 \%$ to the total MSE was obtained, with the Briggs' equations the systematic contribution was $52 \%$.

The un-systematic contribution to the total MSE and its absolute value (of the order of the experimental uncertainty) are indicative of the viability of this kind of numerical approximation for performing dispersive studies over this kind of mid-latitude complex orography and under these winter dispersive conditions.

The systematic errors obtained could be directly related to uncertainties when describing land use and PBL physics. In this sense, further studies should be performed to quantify the effect of using different PBL parameterisations to describe turbulent fields (and, therefore, pollutant dispersion) over mid-latitude complex terrain.

\subsection{Plume impacts on the ground}

If we compare the three simulated $\mathrm{SO}_{2}$ concentrations accumulated throughout the three-day campaign, it is clear that under the aforesaid meteorological conditions there are no qualitative differences between the plume "footprints" when using the three different emission schemes performed (Figs. 13a, b and c). This result is a direct consequence of the very similar dynamic conditions of the simulated emissions (Figs. 5a and b). Obviously, mechanical effects associated with topography are stronger in the case of the $450 \mathrm{~m}$-high fixed emission scheme than in the other cases; even so, the spatial pattern of the accumulated simulated impacts does not essentially vary with respect to the other two emission schemes (Figs. 13a, b and c). In the next section, the simulated mechanical processes associated with the simulated ground impacts leeward of mountains are discussed.

To quantify the ground impacts of the plume aloft on the complex terrain around the emission source, we estimated the accumulated values of the simulated $\mathrm{SO}_{2}$ ground-level concentrations for the different turbulent regimens implemented within the MM5. For this reason, we disaggregated the accumulated concentrations in the different turbulent regimes identified during the whole campaign. In this specific case, calculations were done separately for diurnal hours (free convection regime) and for nocturnal hours (muffled mechanical turbulence regime).

During the nocturnal hours, the accumulated ground-level concentrations show a strong bias towards areas leeward of the mountains, with no simulated impacts near the power plant (Fig. 14c). As a result, the closest simulated impacts are located $45 \mathrm{~km}$ away from the chimney. These results are in agreement with the experimental data that confirm that relevant impacts are located leeward of the mountains (Fig. 14d). In contrast, during the daytime, although the strongest impacts are simulated leeward of the mountains, significant accumulated impacts are simulated in a wider area and closer to the chimney than for the nocturnal hours (Fig. 14a). This is coherent with the behaviour of the measurements in the five sites available (Fig. 14b).

Considering the spatial distribution of the $\mathrm{SO}_{2}$ accumulated magnitudes measured and the location of the five air quality stations, we have grouped them into three different geographical areas with the objective of intercomparing 

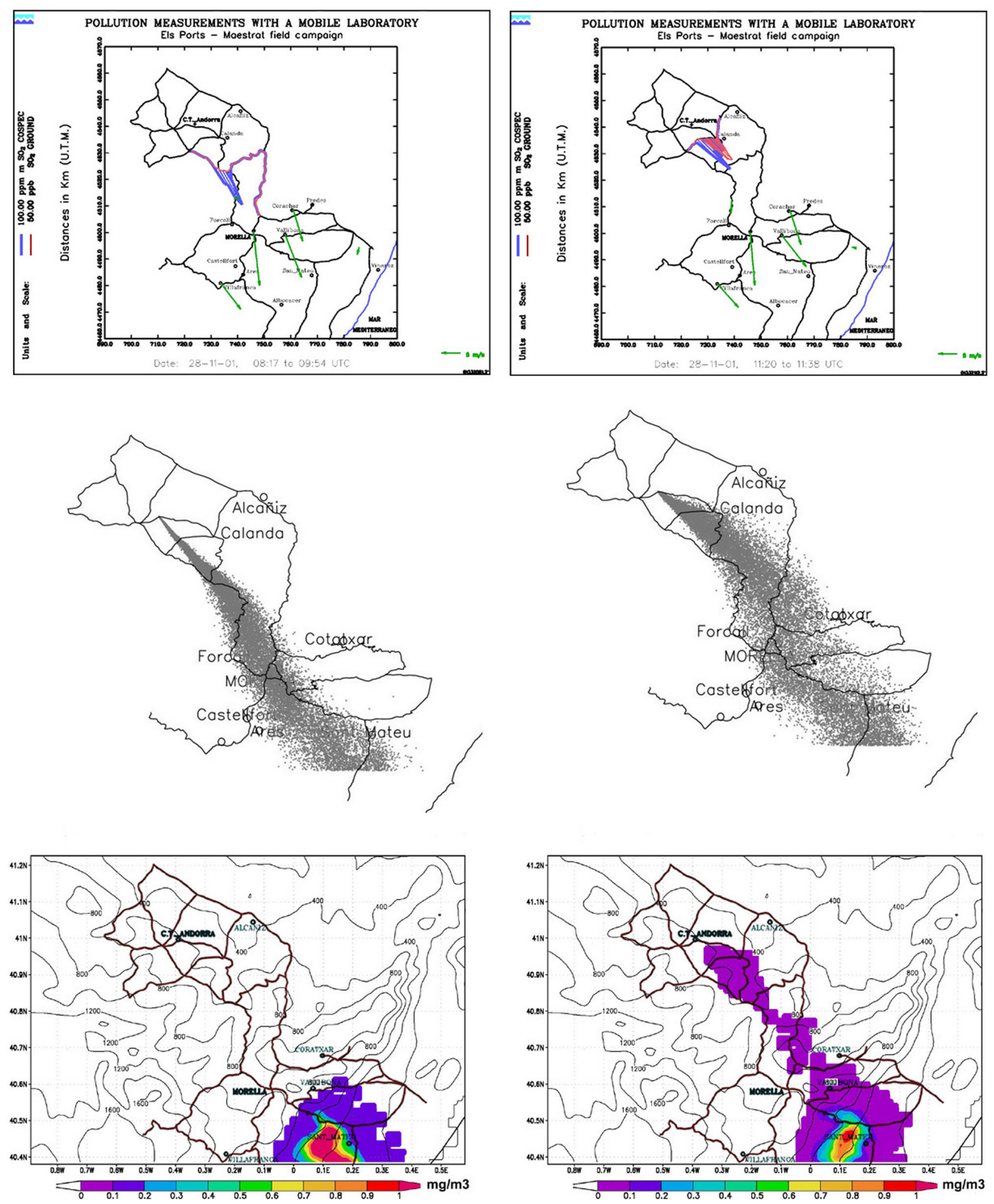

Fig. 9. Third campaign day (28 November 2001). Top (a, b): COSPEC measurements of both the plume aloft (blue line) and its simultaneous impacts on the ground (red line); (a: 08:17-09:54 GMT; b: 11:20-11:38 GMT). Middle (c, d): Simulated Lagrangian distribution at 09:00 GMT (left) and 11:00 GMT (right). Bottom (e, f): Simulated $\mathrm{SO}_{2}$ concentrations on the ground at 09:00 GMT (left) and 11:00 GMT (right). 

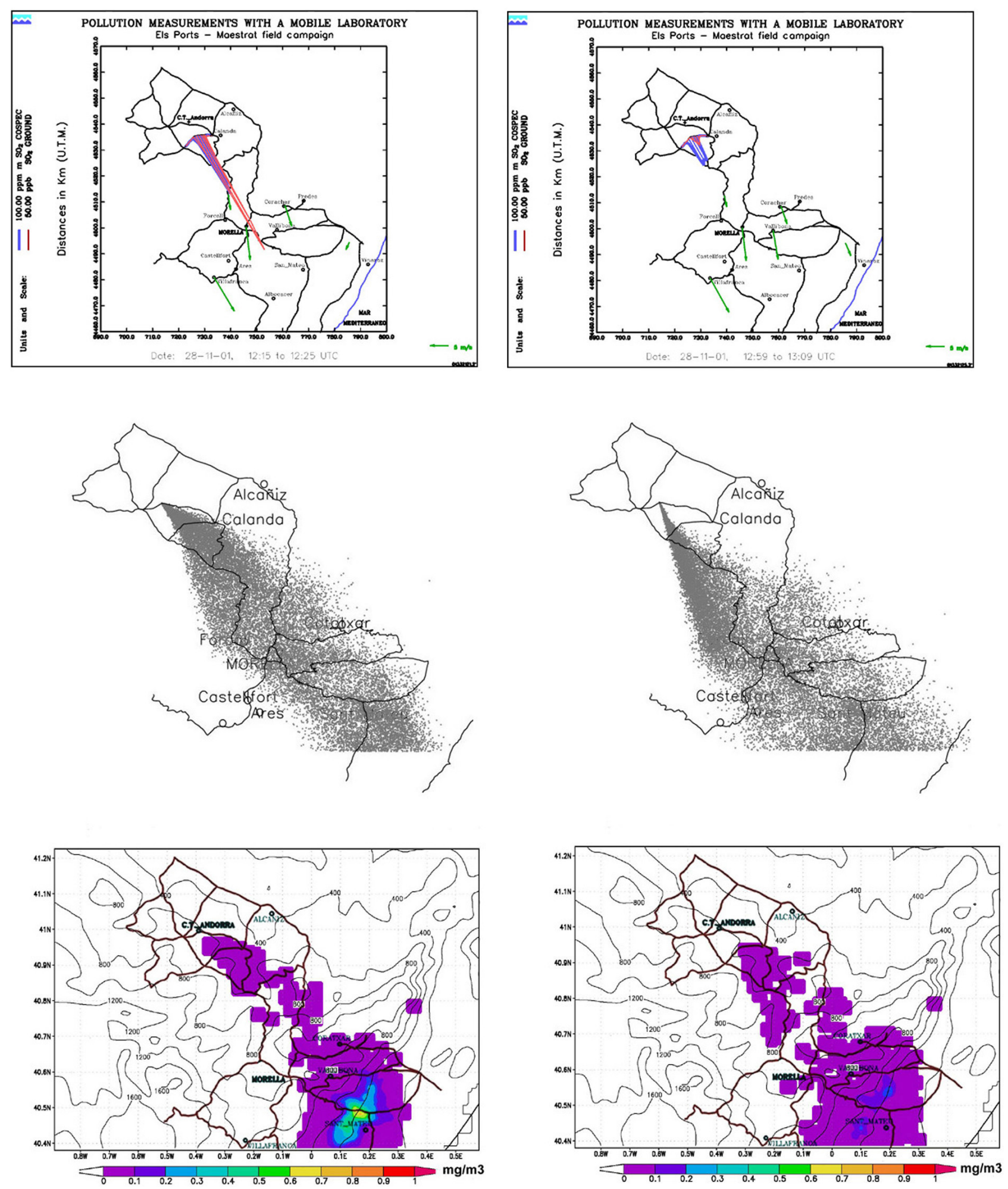

Fig. 10. Third campaign day (28 November 2001). Top (a, b): COSPEC measurements of the plume aloft (blue line) and its simultaneous impacts on the ground (red line); (a: 12:15-12:25 GMT; b: 12:59-13:09 GMT). Middle (c, d): Simulated Lagrangian distribution at 12:00 GMT (left) and 13:00 GMT (right). Bottom (e, f): Simulated $\mathrm{SO}_{2}$ concentrations on the ground at 12:00 GMT (left) and 13:00 GMT (right). 

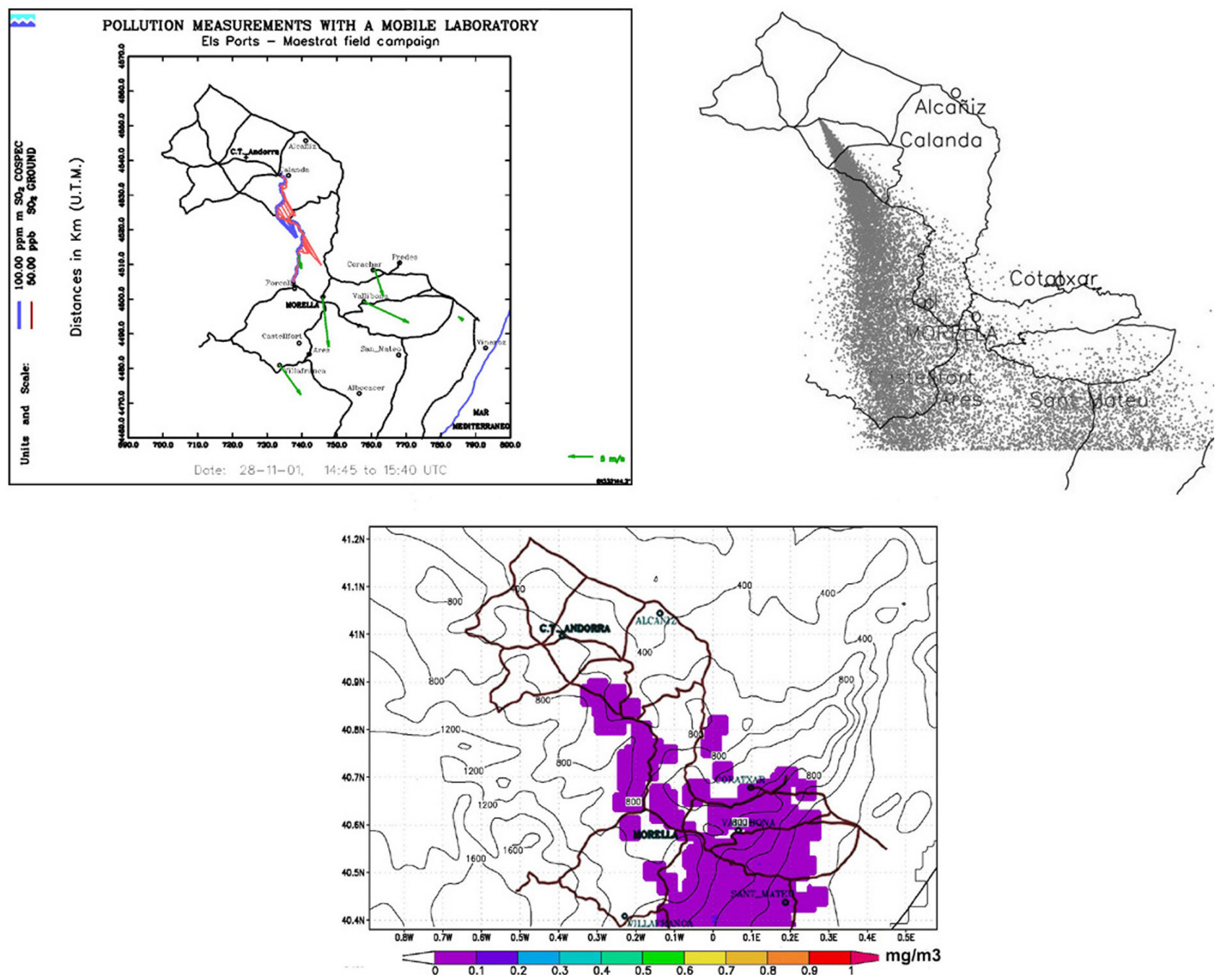

Fig. 11. Third campaign day (28 November 2001). Top-left (a): COSPEC measurements (14:45-15:40 GMT) of both the plume aloft (blue line) and its simultaneous impacts on the ground (red line). Top-right and bottom (b, c): Simulated Lagrangian distribution (bottom) and $\mathrm{SO}_{2}$ concentrations on the ground (right) at 14:00 GMT.

the experimental accumulated concentrations with the LPD model results within the same spatial areas. Figure 2 shows the spatial coverage of the three selected areas $(1,2$ and 3 ), where the corresponding sites recorded accumulated $\mathrm{SO}_{2}$ ground-level concentrations lower than $1000 \mu \mathrm{g} / \mathrm{m}^{3}$, higher than $3000 \mu \mathrm{g} / \mathrm{m}^{3}$ and about $2000 \mu \mathrm{g} / \mathrm{m}^{3}$, respectively. To quantify the differences and the similarities between the simulated and measured impact patterns, diurnal/nocturnal percentual variations of the $\mathrm{SO}_{2}$ ground-level concentrations were calculated as spatial averages within each of the aforesaid zones of the study area (Fig. 2 and Table 3).

From the comparison between the experimental results and the simulated $\mathrm{SO}_{2}$ ground-level concentration fields obtained using the three different emission schemes, we found that zones one and three have comparable diurnal/nocturnal percentual contribution to the total $\mathrm{SO}_{2}$ con- centrations within each zone (Table 3). Both the simulated and experimentally measured results show a diurnal predominance in zone one and a higher nocturnal contribution in zone three. It is interesting to note the high variability of the percental contributions in area 3, depending of the emission scheme employed. This could suggest high spatial and temporal wind field variability at the leeward of the mountains, as small differences in the dynamical conditions of the emissions from the APP induce high variations of the simulated ground-level $\mathrm{SO}_{2}$ concentration.

The discrepancy between the simulated results and the experimental measurements within zone two is due to the direct plume impact at Coratxar station on the night of the 26th. At this site, a very intense plume impact was recorded on the 26th during the nocturnal hours (maximum 1-h average value of $1638 \mu \mathrm{g} / \mathrm{m}^{3}$, not shown). These extremely high $\mathrm{SO}_{2}$ 
Table 3. "Day/night" percentual variation in the mean ground-level $\mathrm{SO}_{2}$ concentrations throughout the field campaign at three different areas Southeast from the APP. Positive variations indicate that diurnal impacts prevail; negative variations indicate that nocturnal impacts prevail. Values are expressed in $\%$ and are calculated from $100 \times\left[\mathrm{SO}_{2}\right]_{\text {day }}-\left[\mathrm{SO}_{2}\right]_{\text {night }} /\left[\mathrm{SO}_{2}\right]_{\text {day }}$. This table is related to Fig. 14 .

\begin{tabular}{|c|c|c|c|c|}
\hline & \multicolumn{4}{|c|}{ Day/night percentual variation of $\mathrm{SO}_{2}$ ground-level concentrations } \\
\hline & Experimental & Emission $450 \mathrm{~m}$ & Emission $700 \mathrm{~m}$ & Briggs emission Briggs \\
\hline AREA 1 & 57.7 & 100.0 & 100.0 & 100.0 \\
\hline AREA 2 & -113.1 & 90.6 & 85.4 & 80.9 \\
\hline AREA 3 & -122.6 & -295.8 & -92.2 & -796.4 \\
\hline
\end{tabular}

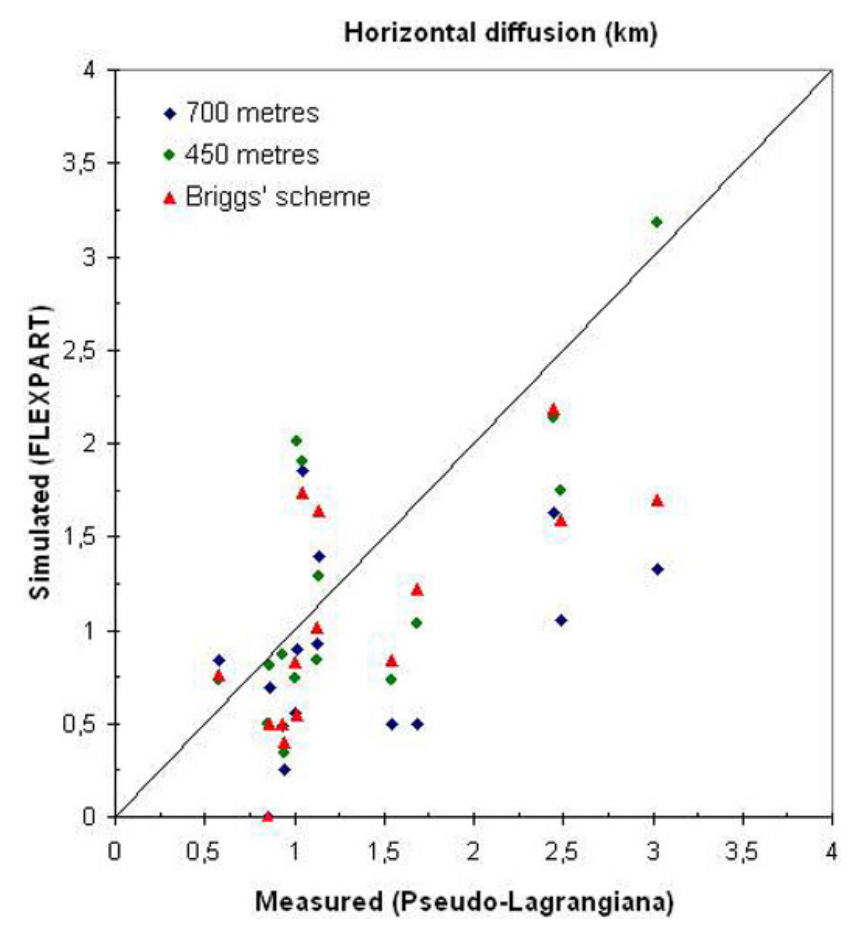

Fig. 12. Comparison between simulated and measured horizontal diffusion for the three different emission schemes performed during the dispersive simulations. Values plotted in this figure are listed in Table 1 (downwind distances between 6 and $33 \mathrm{~km}$ ).

concentration values, together with the low wind speed measured (not shown), indicate that this plume impact was not associated with mechanical turbulence but rather with a direct plume impact on this site. Under very stable conditions with a completely thermalised plume $(55 \mathrm{~km}$ away from the chimney) and with no external forces except gravity, direct plume impacts can occur at mountain heights similar to the plume advective height because the plume cannot change its internal energy to rise up the edge of the mountain (i.e., no variation in the plume external parameters and/or heat transfer with the environment is possible under such thermodynamic states).
To analyse the discrepancy between the simulation and the measurements it is necessary to consider, on the one hand, that this kind of episode (given its local nature) cannot be considered representative of the whole zone two (within which the average $\mathrm{SO}_{2}$ concentration was calculated for the four simulated days). On the other hand, under such stable dispersive conditions (plume advected as a ribbon-type plume) slight deviations between the real and the simulated plume advective direction have a strong impact when comparing simulated and measured local ground-level concentrations (and this limitation worsens even more on complex terrain). Additionally, the analysis of the simulated results indicated the PBL parameterization overestimated the mechanical turbulence, avoiding a stable regime and consequently the presence of very high $\mathrm{SO}_{2}$ concentrations.

\subsection{Orographic effects on the simulated wind fields}

Mesometeorological model behaviour is analysed with respect to wind field perturbations due to complex orography, which drive plume impacts on the ground far away $(>30 \mathrm{~km})$ from the power plant considered in this study. As there are no available vertical measurements over the leeward areas, it is not possible to make a direct comparison between the simulated turbulent fields and those produced within the study area under winter Northwest advective conditions. Nevertheless, description of the simulated wind field is necessary to complement some of the aforesaid physical processes when describing the temporal evolution of $\mathrm{SO}_{2}$ ground-level concentrations on the mountainous and coastal sites located Southeast of the APP.

For stationary flows, the development of trapped leewaves (leeward of mountain barriers) is favoured when a vertical increase in wind speed exists, i.e., when stability decreases with height. Scorer (1997) showed how these requirements are equivalent to the vertical decrease with height of the Scorer parameter $\left(l^{2}\right)$ :

$$
l^{2}=\frac{g}{U^{2}} \frac{1}{\theta} \frac{\partial \theta}{\partial z}-\frac{1}{U} \frac{\partial^{2} U}{\partial z^{2}}
$$



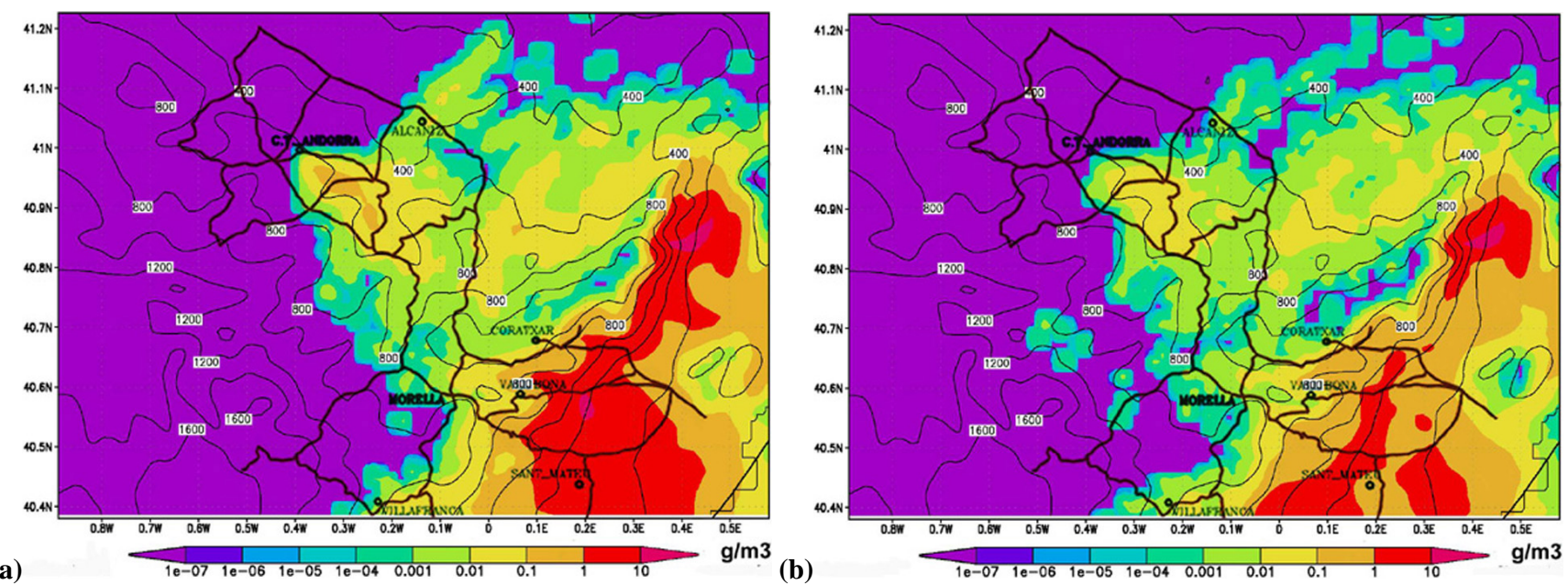

(a)

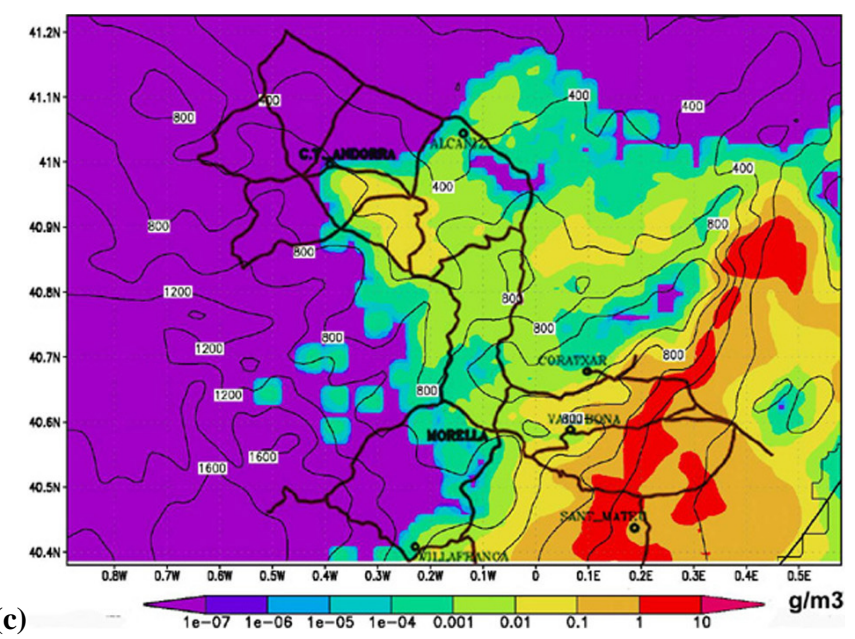

Fig. 13. Simulated plume footprint when using the three different emission schemes (top left, (a), $450 \mathrm{~m}$-height; top right, (b), $700 \mathrm{~m}-$ height; and bottom, (c), Briggs' plume-rise scheme). Figures represent the $\mathrm{SO}_{2}$ ground-level concentration accumulated during the four-day simulated period (25-28 November).

where

$U$ is the mean wind speed, perpendicular to the obstacle (or mountain).

$g$ is the gravity acceleration.

$\theta$ is the potential temperature.

As evidenced previously, within the context of complexterrain air quality simulations, the ground-level plume impacts simulated leeward of the mountains represent one of the most relevant features of the dispersion model results and will strongly depend on the meteorological fields resolved by the mesoscale model (Liu and Carroll, 1996; Gangoiti et al., 2002).

To visualise the vertical distribution of the Scorer parameter obtained from the simulated meteorological fields (Eq. 1), we analysed two transversal sections (at constant $0.05^{\circ} \mathrm{E}$ longitude and $40.43^{\circ} \mathrm{N}$ latitude) from the previously pre- sented simulations. The simulated meteorological data for 28 November show a decrease in the Scorer parameter leeward of the mountains from $1000 \mathrm{~m}$ a.g.l. for both transections during the whole day (Figs. 15, where vectors represent the horizontal wind field). In contrast, over the Ebro valley (around $41^{\circ} \mathrm{N}$ ) we observe an extensive area within the lower atmospheric layers with low values of $l^{2}$ (increasing with height), indicating that in these semi-flat areas the development of this kind of secondary circulation is poorly favoured under these metorological conditions.

The effect of these leewaves on elevated plumes was documented empirically within the Iberian Peninsula using the emissions from the Santurtzi power plant (Millán et al., 1987); the observed dynamic behaviour was described as plume "loopings" rapped by "turbulent cavities" produced leeward of a $455 \mathrm{~m}$-tall hill. 

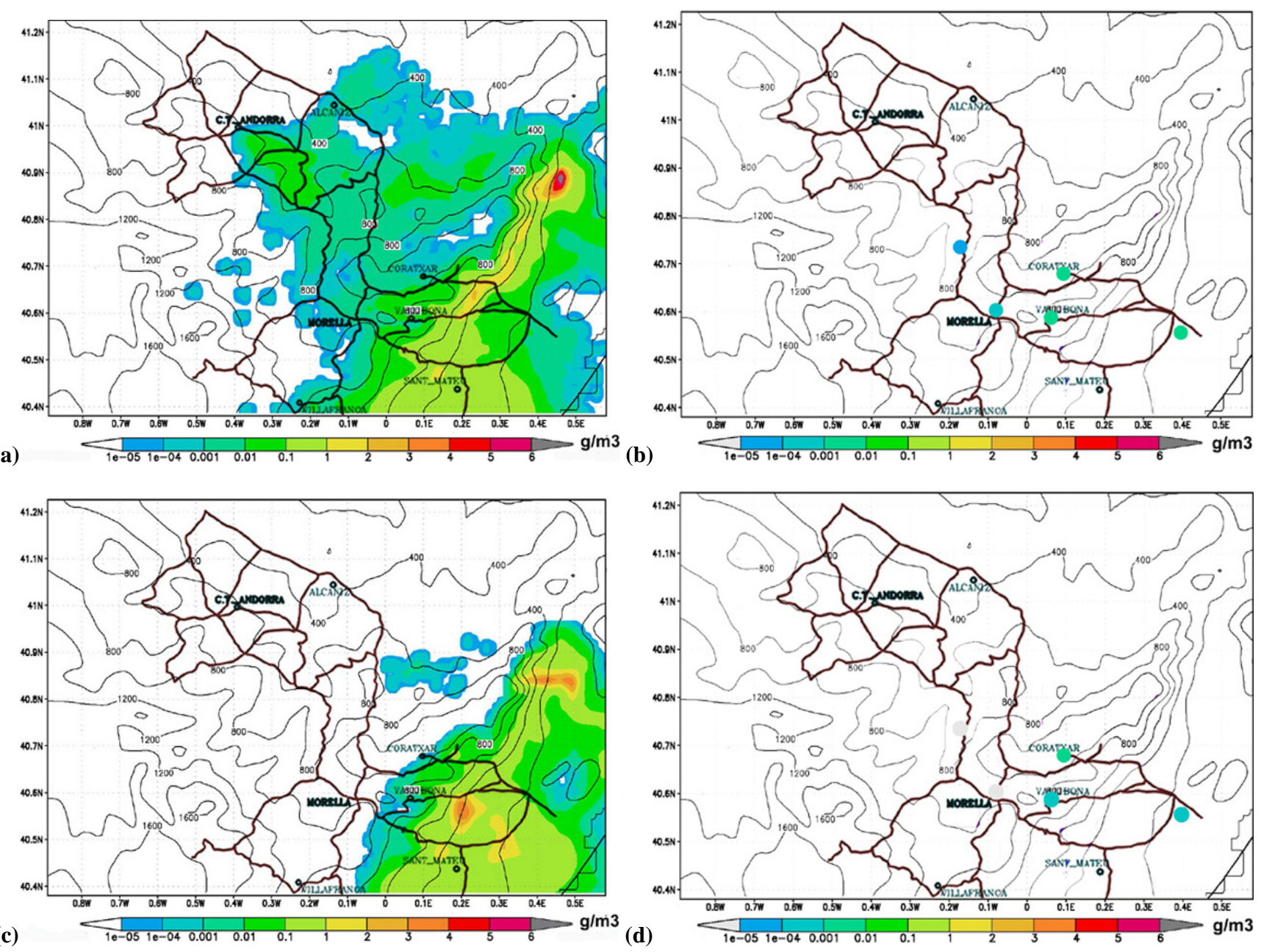

Fig. 14. Accumulated diurnal (top-left, a) and nocturnal (bottom-left, c) ground-level concentration fields obtained from the dispersive simulations performed with the $700 \mathrm{~m}$ constant height scheme. Experimental diurnal (top-right, b) and nocturnal (bottom-right, d) accumulated $\mathrm{SO}_{2}$ concentration at five air quality stations, Northeast of the APP. Accumulation was calculated for the four-day simulated period (25-28 November).

In our case, the LPD model was able to "interpret" the secondary dynamics simulated by the mesometeorological model and differentially transport the plume in a ribbon-type plume that produces eventual, intermittent and very local impacts on the ground (Figs. 16, where the plume transversal sections are presented at the same time and at the same constant latitude and longitude that for the vertical Scorer parameter distribution). Despite this capability, high bias between experimental and simulated percentual contributions in area 3 has been found (Table 3), probably due to the interaction of different mesoscale forcings that could be unresolved by the model.

The high intensity of the ground impacts at these distances from the chimney are due, as aforementioned, to the low vertical and transversal dispersion of the plume aloft (ribbontype plume) during its advection from the chimney, and, as shown in this last section, to the mechanical instabilities looping the ribbon-type plume vertically once it reaches the mountain barriers.

\section{Conclusions}

The availability, since 1994, of an extensive database with systematic tracking of a $\mathrm{SO}_{2}$-plume emitted from a power plant, has allowed the identification of one of the field campaigns that best exemplifies the most recurrent winter scenario in a mid-latitude and topographically complex terrain area.

A direct quantitative comparison has been performed between the dispersive conditions simulated by the coupled numerical system MM5+FLEXPART and two combined databases consisting of (1) data from a traditional surface 


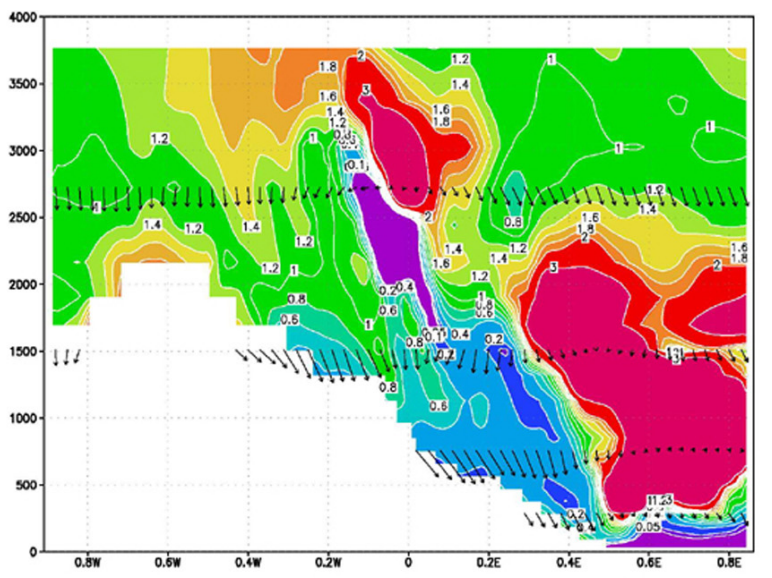

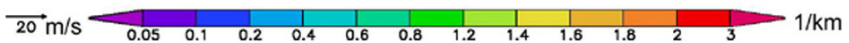
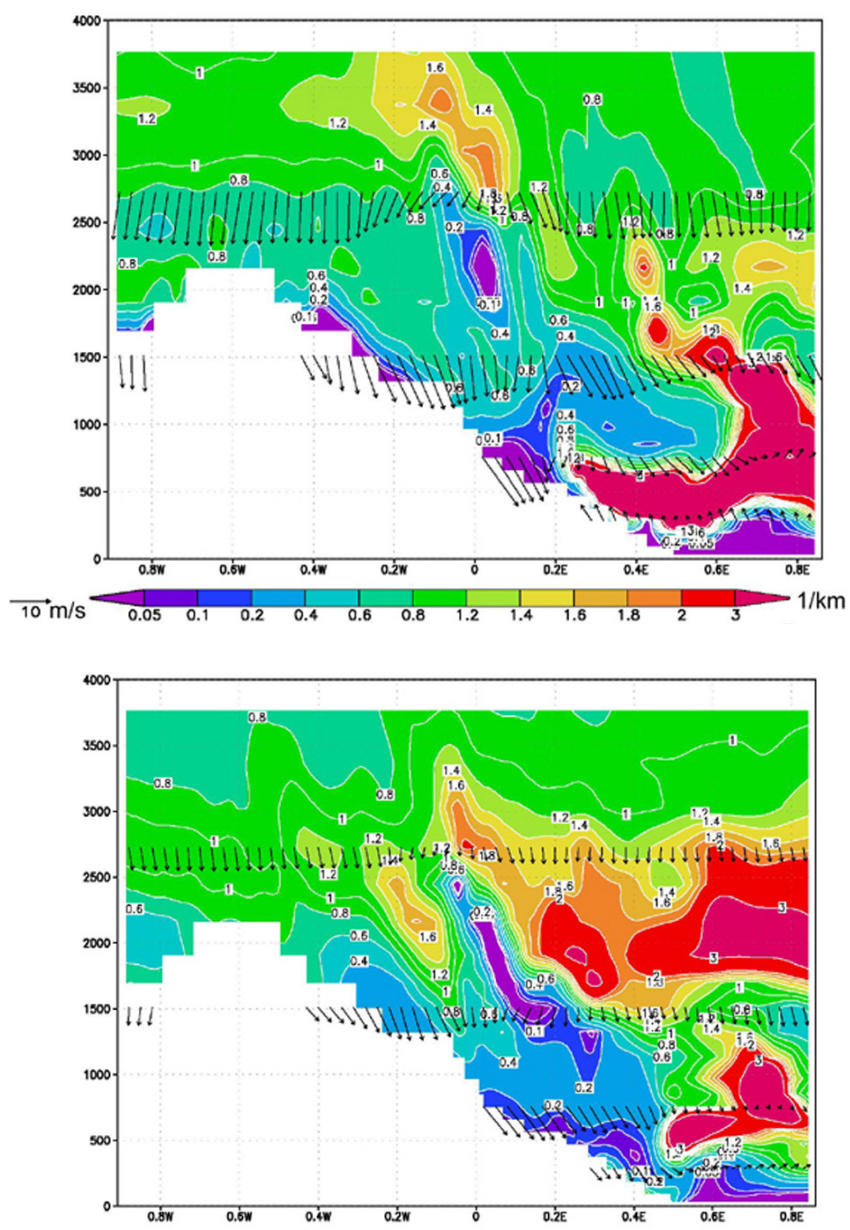

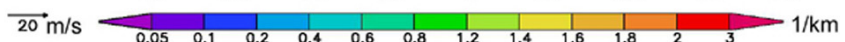
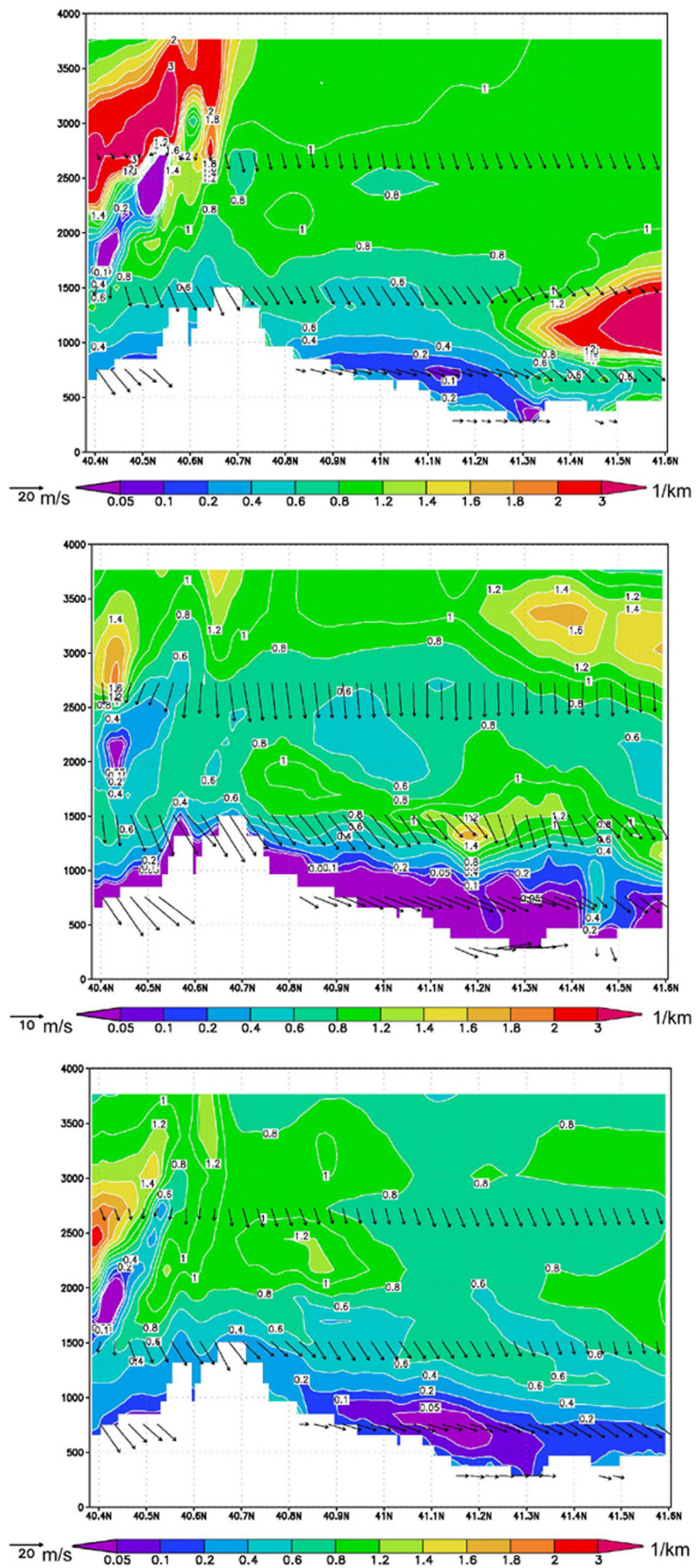

Fig. 15. Vertical distribution of the Scorer parameter $\left(\mathrm{km}^{-1}\right)$ from the meteorological simulations for 28 November. Vectors indicate wind field. The left column corresponds to a fixed latitude plane $\left(40.43^{\circ} \mathrm{N}\right)$ and the right column corresponds to a fixed longitude plane $\left(0.05^{\circ} \mathrm{E}\right)$. The first row corresponds to 06:00 GMT, the second row to 13:00 GMT, and the third row to 18:00 GMT.

Air Quailty Network (with high temporal resolution) and (2) data from simultaneous measurements of $\mathrm{SO}_{2}$ spatial distri- butions aloft and on the ground (with a high spatial resolution). 

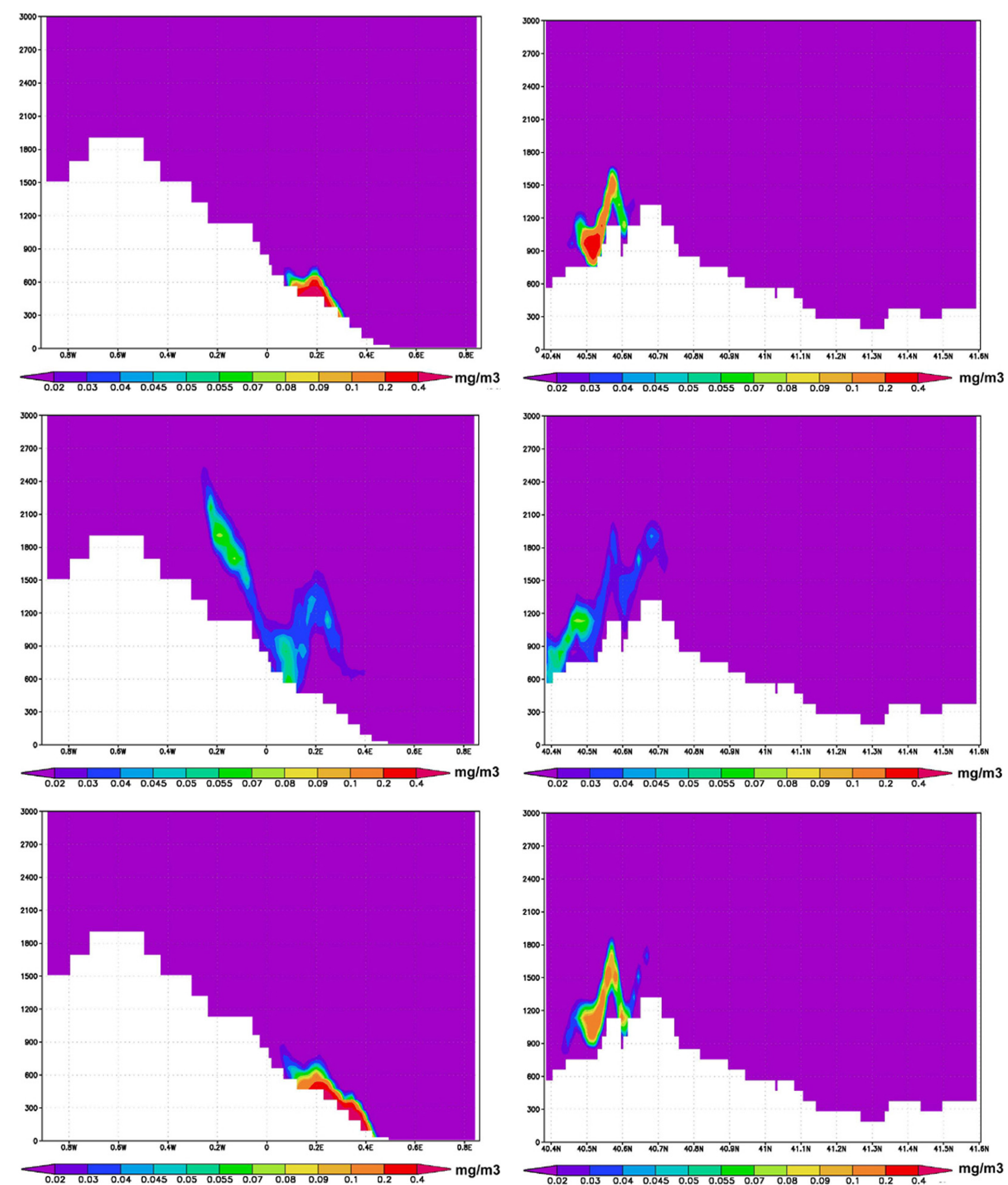

Fig. 16. Vertical distributions (left column, constant latitude $40.43^{\circ} \mathrm{N}$; right column, constant longitude $0.05^{\circ} \mathrm{E}$ ) of the simulated $\mathrm{SO}_{2}$ plume for 28 November. The first row corresponds to 06:00 GMT, the second row corresponds to 13:00 GMT, and the third row corresponds to 18:00 GMT. 
The availability of these combined databases represents a clear advantage over the information provided only by fixed ground-level monitoring stations for atmospheric pollutant control. Ground-level pollutant concentrations on complex terrain present high spatial and temporal variability that is difficult to simulate and compare directly with fixed groundlevel measurements and new ways of interpretation and assessment of air quaility on complex terrain must be looked for.

A new methodology (based on Pseudo-Lagrangian averages) has been developed to calculate the horizontal turbulent diffusion of the measured pollutant spatial distribution aloft throughout the day.

This new methodology, together with a traditional procedure for the air-quality intercomparison between experimental and simulated air-quality results, has been found to be useful for a detailed validation of the skills of the aforementioned coupled system MM5+FLEXPART in the simulation of the atmospheric pollutants behaviour.

Moreover, this study shows how the integration of the aforementioned experimental data with the validated numerical system can give a complementary view for the interpretation of meso-meteorological processes and for the quantification of the daily evolution of the dispersive conditions on a complex-terrain region.

Under Northwest winter advective conditions, the coupled numerical system MM5+FLEXPART has been able to reproduce the most relevant dispersive features of an elevated plume. The results show that the coupled models are able to predict the plume integral transport from the Andorra power plant on very complex terrain. Linked to the orographic features, the simulated plume impacts on the ground more than $30 \mathrm{~km}$ away from the stack because of the leewaves simulated.

These results have been possible thanks to the availability of simultaneous monitoring, aloft and on the ground, of both the $\mathrm{SO}_{2}$ spatial distribution emitted from a point source and its impacts on the ground (reaching distances up to $80 \mathrm{~km}$ from the chimney).

Using available measurements of the $\mathrm{SO}_{2}$ concentration aloft and on the ground, and performing different numerical simulations, we were able to identify and simulate the following processes:

1. Integral plume transport under winter advective conditions over complex terrain.

2. Ground impact patterns along the arc defined by the preferred plume transport directions aloft: 1) Impacts close to the chimney driven by diurnal convective and mechanical turbulence; and 2) impacts far away from the chimney (more than $80 \mathrm{~km}$ ) driven by orographic effects (mechanical turbulence).
3. The plume differential transport resulting from secondary circulations of the synoptic advective regime on complex terrain.

These results permitted a comparison between experimental and simulated transversal dispersion with an "index of agreement" of 80-90\%, within distance ranges of 6 to $33 \mathrm{~km}$ from the stack. Moreover, the variation in the accumulated ground-level concentrations for the different plume-rise schemes is found to be larger far away from the chimney (about $80 \mathrm{~km}$ ) than in intermediate areas (ranging from 40 to $60 \mathrm{~km})$.

The dispersive simulations performed had a nonsystematic contribution to the total MSE ranging from $29 \%$ to $88 \%$ depending on the plume-rise scheme; moreover, the absolute errors range from $0.53 \mathrm{~km}$ to $0.84 \mathrm{~km}$, i.e., lower than the available experimental accurancy. Both statistical results corroborate that the coupled numerical model (MM5+FLEXPART) is a suitable tool to perform dispersion research on complex terrain in mid-latitude winter conditions perturbed by local-to-meso scale secondary circulations driven by topography.

Systematic errors were found to be highly dependent on the plume-rise scheme implemented; nevertheless, throughout this study these systematic errors were also attributable to limitations on the PBL parameterisation and the land use description. In this sense, further research is needed to quantify the effect of using different PBL parameterisations to describe the turbulent field on complex terrain (and, therefore, pollutant dispersion). The versatility of the MM5 mesometeorological model when using different PBL schemes is an additional motive for using this tool in the aforementioned research.

\section{Appendix A}

\section{Pseudo-Lagrangian data processing methodology for remote sensing measurements}

In the plume-measurement strategy used in the field campaign presented in this paper, mobile units (vehicles instrumented with a COSPEC) make transects around the emission source at different distances (Fig. A1). Measurements must be taken throughout the day to record any changes that might occur in the plume transport direction or in the dispersive conditions (Millán, 1978a). To obtain the dispersive parameters implicitly contained in the experimental data recorded with the COSPEC, Eulerian and Pseudo-Lagrangian averages must be carried out. Each of these presents the following features (Millán, 1978b):

- Eulerian average: This average, georeferenced or fixed to terrestial coordinates, shows the meandering of the centre of gravity of the plume throughout the averaging 


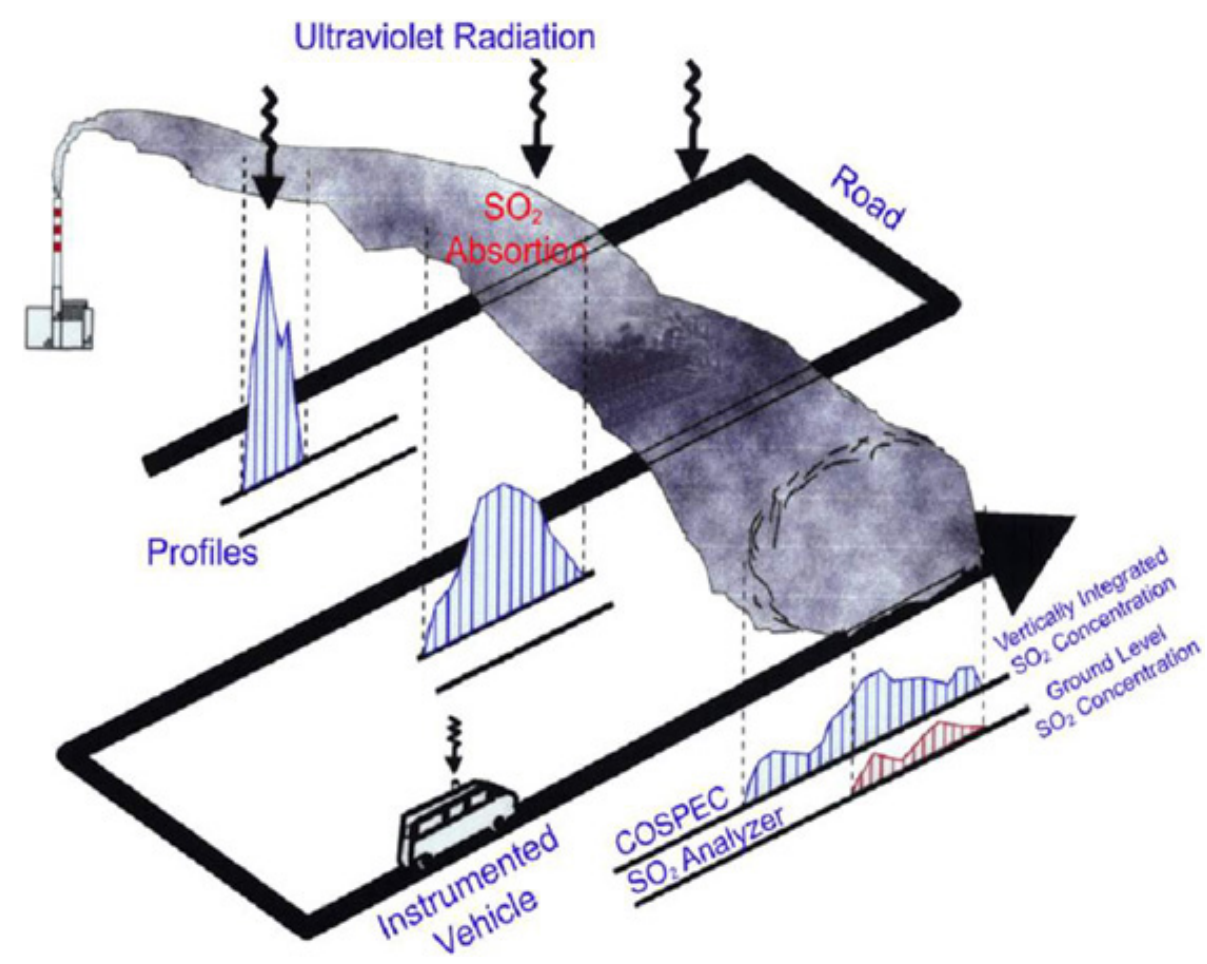

Fig. A1. Plume tracking strategy. A vehicle instrumented with a COSPEC and a ground-level analyser makes transects at different distances from the emission source for the whole day.

time. It corresponds to the average plume observed at the ground stations.

- Pseudo-Lagrangian average: This average is made with the coordinates related to the centre of gravity of each profile; thus, meandering effects are not taken into account. This profile, averaged in time but not in space, shows the relative diffusion of the plume and keeps its morphologic features: bifurcation, directional shear effect, wind-speed shear effect (Kurtosis), etc.

The geometrical requirements (summarised in this appendix) have to be taken into account during the averaging process to guarantee the significance of the averaged profiles; i.e., it is necessary to establish control mechanisms to ensure correspondence between the profiles projected over the plane perpendicular to the mean plume transport direction (defined as the effective plane, Fig. A2) and those that would be obtained by measuring directly over that plane (Millán et al., 1976; Hoff and Gallant, 1985).

\section{A1 Averaging procedure}

When several plume profiles were registered consecutively (along the same road span), their spatial average was calculated (Eulerian average over the road). This averaged (Eulerian) profile of the (vertically integrated) concentration distribution includes both the dispersive features of the averaged plume and the geometrical characteristics of the road used during the measurements. To eliminate this second contribution, it is necessary to estimate the instantaneous plume on the effective plane (the plane perpendicular to the mean plume transport direction). This plane is determined by calculating the line connecting the chimney and the centre of gravity of the mean profile obtained on the road, c.g.r (Fig. A3). This line is considered the average axis of the plume or the mean plume transport direction (Millán et al., 1976).

When each of the experimental profiles obtained over the same road span is projected onto the effective plane, a new Eulerian average is performed on the effective plane and a new centre of gravity is calculated, c.g.pp (in general, this new centre of gravity will not coincide with the projection of the c.g..r on the effective plane). In addition, the centres of gravity of each of the projected profiles are calculated, c.g..pi.

A pseudo-Lagrangian average is obtained by superimposing the c.g..pi; in this way, the new averaged profile has no connection with the coordinates of the road projected on the effective plane (Millán et al., 1976). This last distribution contains only information on the concentration values at different (relative) distances from its centre of gravity. This distribution has no spatial information because it is the product of a temporal average (not a spatial one). 


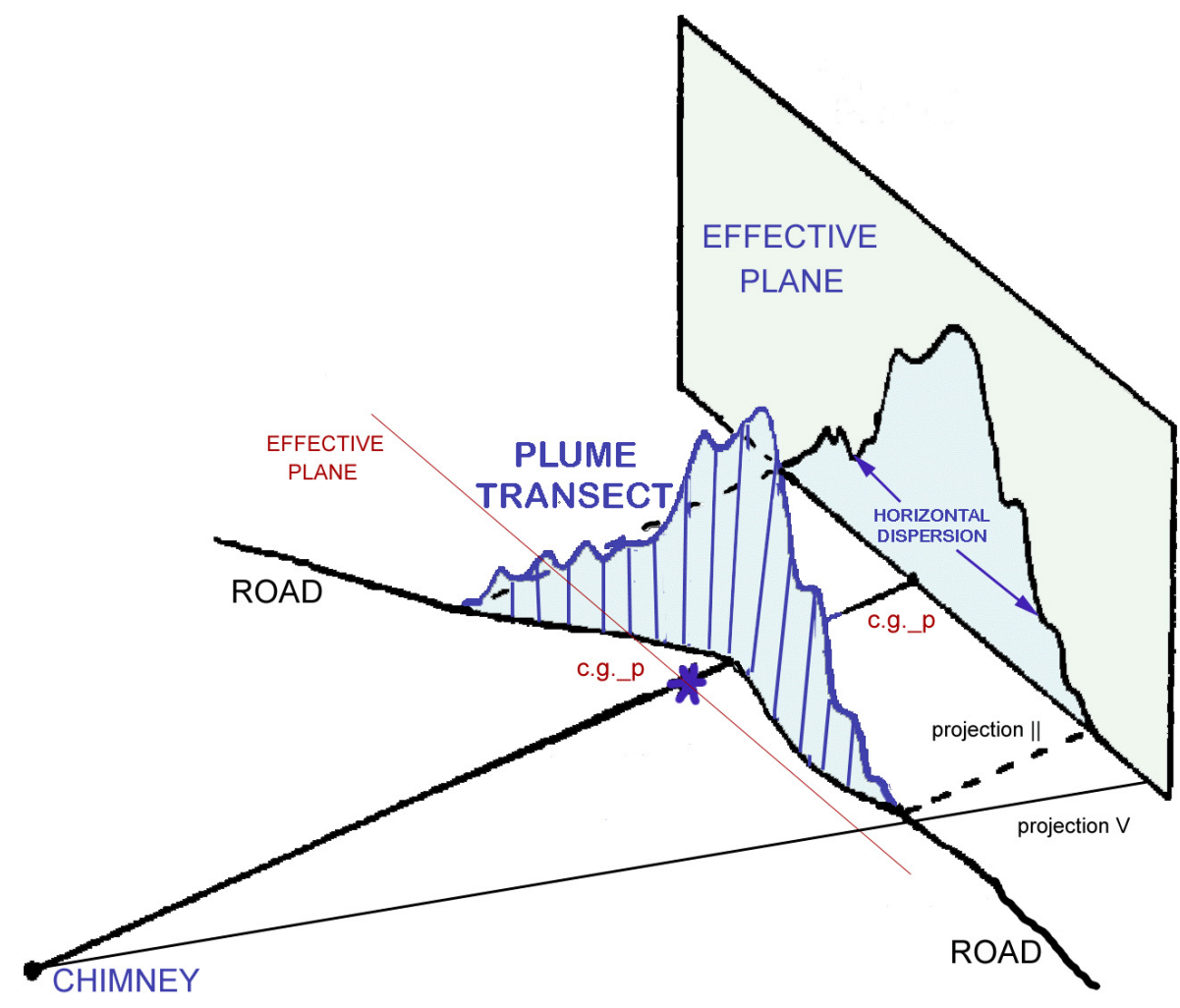

Fig. A2. Schematic representation of the definition of "effective plane", starting from a vertically integrated distribution recorded with the COSPEC along a road span. C.g.-p is the center of gravity of the distribution projected on the effective plane.

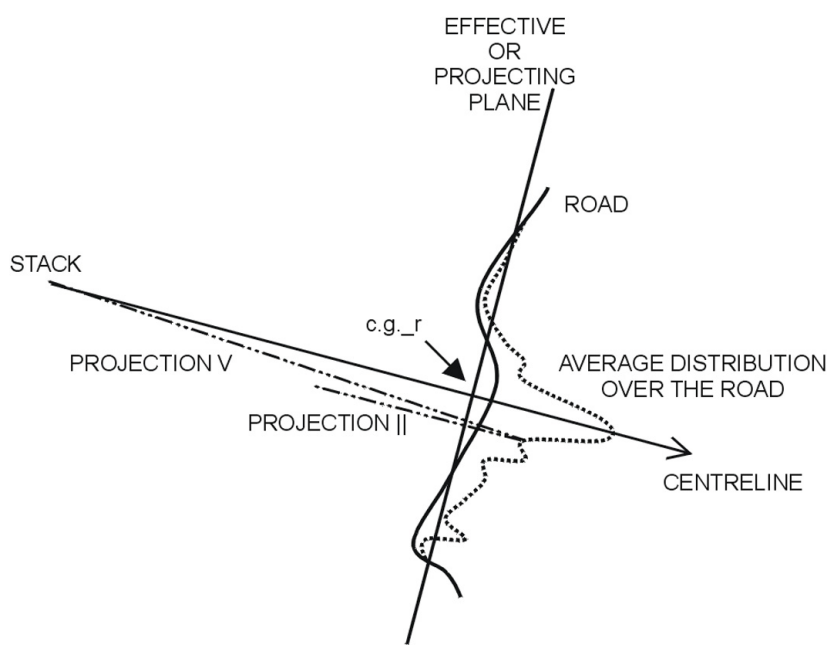

Fig. A3. Schematic representation of the definition of the "effective plane" and the "centreline", starting from a vertically integrated distribution recorded with the COSPEC along a road span. C.g._r is the center of gravity of the distribution measured along the road.

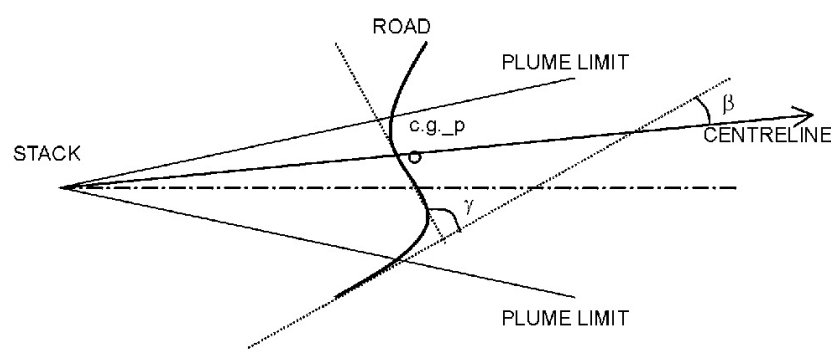

Fig. A4. Schematic representation of the definition of "angles $\beta$ and $\gamma$ " definition, starting from the road span and the centreline. C.g.pp is the center of gravity of the distribution projected on the effective plane.

\section{A2 Geometrical restrictions}

Based on the large number of plume profiles obtained in the $70 \mathrm{~s}$ from a $380 \mathrm{~m}$-tall chimney ${ }^{5}$, Millán et al. (1976) and Millán (1978b) established geometric criteria to assure "realistic" projected profiles. These studies were performed for four different stability classes (from very unstable to stable) and for different road geometries. They justified the general

\footnotetext{
${ }^{5}$ International Nickel Company (INCO) chimney, located at Sudbury (Ontario, Canada).
} 


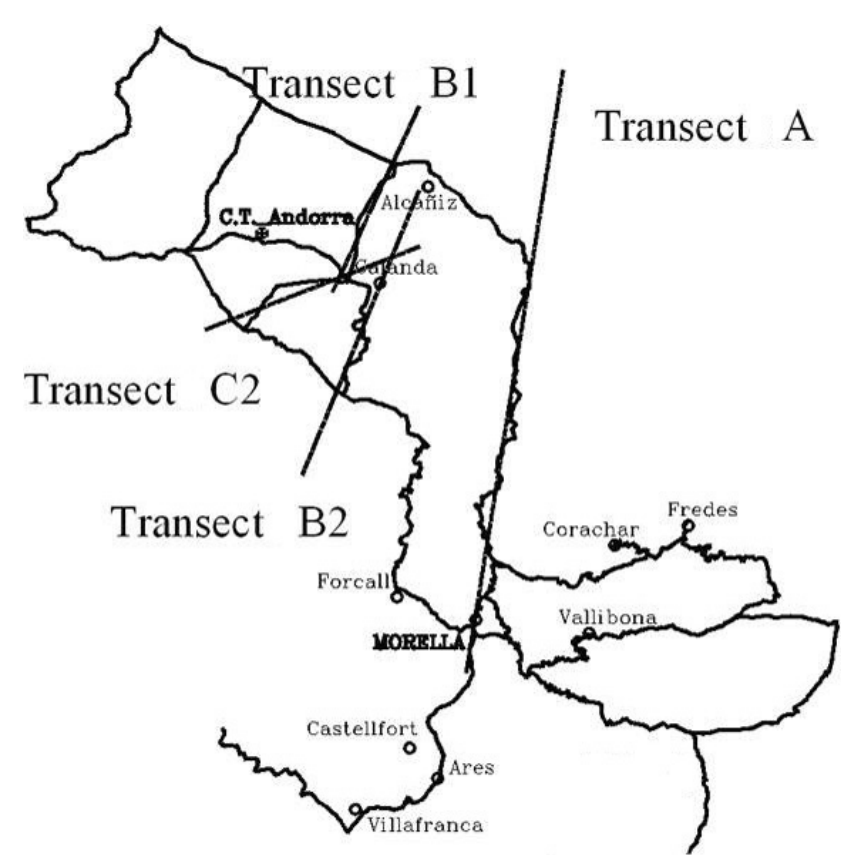

Fig. A5. Straight lines defined on four selected transects from the available road network.

geometric restrictions (just described herein), and they concluded that only two angles were restrictive: the maximum angle between the most divergent directions in the road span used during the measurements, $\gamma$ (i.e., between road curves), and the minimum angle between the plume axis and the road span used, $\beta$; (Fig. A4).

In this way, some road-geometry restrictions are established (transects that are not too curvy or that lack long spans between sharp curves), and the angle between the road and the plume axis is also limited (only considering the cases when this angle tends to $90^{\circ}$ ). The restrictive values for the different angles depend on the dispersive conditions (atmospheric stability); these are more conservative when the instability is higher (i.e., higher dispersion, shear effects and meandering). To avoid considering profiles affected by shear effects, different publications (Millán et al., 1976) discuss in depth the general geometrical restrictions needed. Table A1 summarizes the results obtained by Millán et al. (1976).

Given the configuration of the roads used in the field campaigns studied herein, the above geometrical restrictions were particularized to simplify their practical implementation (Palau et al., 2001). Moreover, from the aforementioned criteria, the following were designed and applied:

\section{A2.1 Regarding the plume axis}

An experimentally-tracked plume is rarely symmetrical to any axis or point (if it is an instantaneous plume or if it is the product of some kind of average). In this sense, the plume axis can be considered the central line of the distribu-
Table A1. Generic geometrical limits to be fulfilled for a reliable projection on the effective plane (depending on the atmospheric stability class).

\begin{tabular}{lcc}
\hline $\begin{array}{l}\text { Atmospheric } \\
\text { stability class }\end{array}$ & Minimum angle $\beta$ & Maximum angle $\gamma$ \\
\hline Stable & $10^{\circ}$ & $120^{\circ}$ \\
Neutral & $20^{\circ}$ & $100^{\circ}$ \\
Unstable & $30^{\circ}$ & $70^{\circ}$ \\
Very unstable & $40^{\circ}$ & $50^{\circ}$ \\
\hline
\end{tabular}

tion; nevertheless, this definition subordinates the plume-axis determination to the measurement method (or to the plumediffusion theoretical treatment). Several different strategies have been presented in the literature: some authors have used the maximum of the concentration values as the locus of the plume axis (Slade, 1968) while others consider the center of gravity of the experimental concentration distribution (Csanady, 1973).

Throughout this study, both axes of the averaged plume on the road were considered (one calculated from the concentration maximum and the other from the locus of the centre of gravity, c.g.r).

Only those profiles with angles (between both axes) lower than ten degrees were considered. Averaged profiles with any ambiguity in the definition of their axis (with angles higher than ten degrees) were discarded. In this way, askew distributions caused by directional shear were not considered.

In order to define the effective plane for the plumes fitting this geometrical restriction, the axis determined by the centre of gravity was considered (as recommended by Millán et al., 1976).

A2.2 Regarding the geometry of the road used in the field campaigns

Because of the particular distribution of the road network and the dispersive scenario chosen (winter advection from the NW, with stability classes E and D), for the "Els PortsMaestrat" field campaigns we selected four transects along the available road network (Palau et al., 2001). Each of these defines a quite straight line (Fig. A5). Along these roads, the effects of high $\gamma$ angles can be underestimated. This is reasonable because spans between curves subtending a higherthan- $100^{\circ} \gamma$ angle can be found along all four transects, and they are always shorter than one kilometer in length (characteristic, as in this case, of mountain-road networks in complex terrain with very sharp and close curves). For this reason, the spatial resolution selected for the plume measurements was five hundred meters, and road irregularities below that size are averaged.

On the other hand, for these four straight lines, the estimation of the $\beta$ angle is also simplified. In this context, $\beta$ is the 
Table B1. Frequency (\%) in which the plume aloft is advected in a determined direction (wind roses at the mean plume advection height) The "plume roses" were obtained as annual and seasonal averages for the period 1995-2004.

\begin{tabular}{lrrrrrrrr}
\hline & N & NE & E & SE & S & SW & W & NW \\
\hline Total (1995-2004) & 8.3 & 9.1 & 22.8 & 32.2 & 5.5 & 2.7 & 8.4 & 11.1 \\
Summer & 8.7 & 5.5 & 11.9 & 23.0 & 7.9 & 6.3 & 18.2 & 18.6 \\
Winter & 5.8 & 8.9 & 26.0 & 45.9 & 2.8 & 0.2 & 3.2 & 7.2 \\
\hline
\end{tabular}

angle subtended by the fitted line obtained from the road and the axis of the averaged plume (averaged on the road). As this study is centred in stable to neutral scenarios, the profiles considered were those with $\beta$ higher than (or equal to) $20^{\circ}$ (as indicated in Table A1).

\section{Appendix B}

\section{Statistical description of the plume integral advection aloft}

The "classic" meteorological approach to the dispersion for air pollutants on a region is based on a preliminary analysis of the surface wind-field regimes, in order to provide "recurrent" wind fields for transport calculations (e.g., Zaremba and Carroll, 1979). Besides, by using the plume transport direction aloft as a tracer of opportunity of the wind field at the plume (air pollutants) transport height, it is possible to identify the diurnal advective regimes in the mid-troposphere. Previous studies in different climatological and geographical regions have already used plume transport directions aloft to track the main dispersive characteristics and daily evolution of the windfield at the plume transport height (Millán, 1979; Guillot et al., 1979; Chung et al., 1981; Hoff et al., 1982; Portelli et al., 1982; Millán et al., 1987; Eastman et al., 1995; Palau et al., 2005).

This availability of measurements aloft, obtained by means of a vehicle equipped with a COSPEC remote sensor, represents a clear advantage over the information provided by the fixed ground-level monitoring stations for atmospheric pollutant control, especially on mid-latitude complex terrain (where vertical wind directional shear is the most persistent pattern). A statistical analysis of the plume transport directions between January 1995 and December 2004, was used to obtain an averaged (statistical) representation of the main windfield advective features aloft throughout the four seasons of the year.

From the 3236 different $\mathrm{SO}_{2}$ distributions aloft (obtained with the COSPEC around the APP), we calculated the annual and seasonal average frequency distributions of the plume transport directions (Fig. B1). A seasonal intercomparison provided the following statistical evidence with regard to the advective behaviour of the plume aloft (Fig. B1 and Table B1):

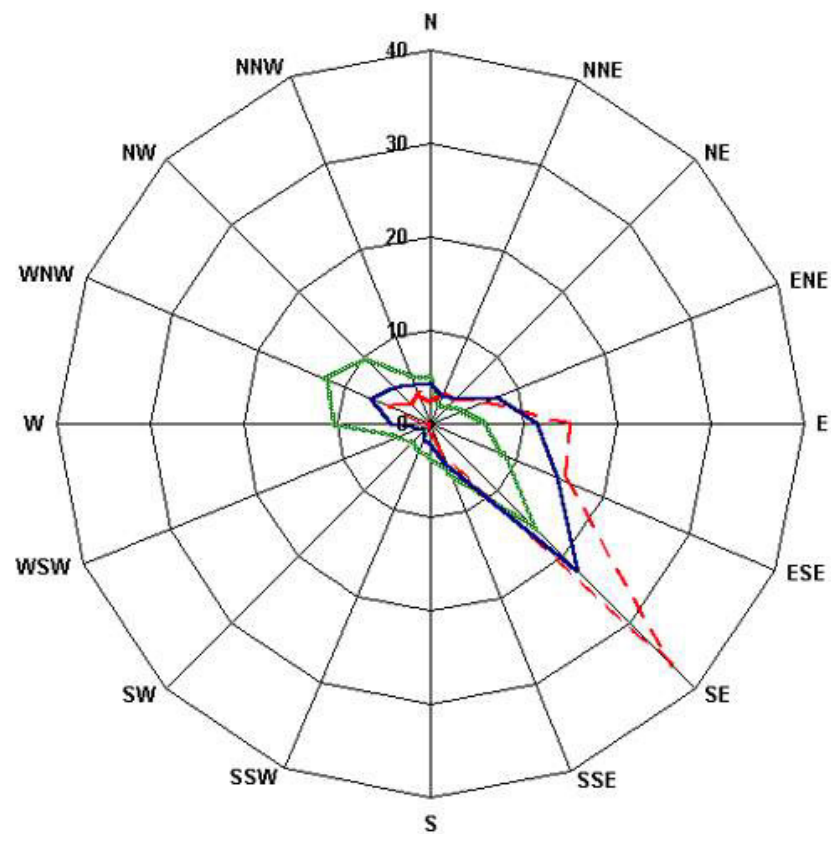

Fig. B1. Frequency $(\%)$ in which the plume aloft is advected in a particular direction (wind roses at the mean plume advection height). The 'plume roses' were obtained as annual and seasonal averages for the period 1995-2004. The blue line is the "annual" frequency of the plume transport direction aloft; the dotted red line is the "winter" frequency of the plume transport direction aloft; and the green line is the "summer" frequency of the plume transport aloft.

Our statistics on plume transport aloft evidence a clear predominance of the Southeast transport direction $\left(45^{\circ}\right.$-to- $125^{\circ}$ sector, following a clockwise criteria starting from the North) during the autumn-to-spring period. Only during the summer period are the transport directions from SE and SW statistically equiprobable (both transport frequencies are similar).

During wintertime, from a statistical point of view, $80 \%$ of the plume transport directions measured aloft are located around the second meteorological quadrant (transport towards the SE from the chimney); Fig. B1 and Table B1. This statistical evidence arises because of the recurrence of Northwest advective conditions. This seasonal dispersive scenario is the natural consequence (from a climatological point of view) of the gradual migration (during the late summertime and autumn) of the northern lows towards mid latitudes and 
the corresponding retreat of the Azores high pressure system from Iberian Peninsula latitudes. Under this seasonal dispersive scenario, the plume aloft is advected by the general wind circulation driven by Atlantic lows flowing Northwest to Southeast onto the Iberian Peninsula, and/or under nocturnal drainage conditions channelled by the Ebro basin towards the Mediterranean sea. Only $20 \%$ of the experimental measurements tracked the plume aloft flowing inland (towards Northwest).

Acknowledgements. The authors would like to acknowledge the people from the CEAM Foundation who participated in the field measurements campaign. The CEAM Foundation is supported by the Generalitat Valenciana and BANCAIXA (València, Spain). This study has been partially funded by the Conselleria de Cultura (Generalitat Valenciana, SPAIN) research project "MEDICO" - GV04B-069, and by the Conselleria de Territori i Habitatge (Generalitat Valenciana, SPAIN).

Edited by: S. Galmarini

\section{References}

Albizuri, A.: Métodos de diagnóstico y predicción de episodios de contaminación atmosférica: aplicación a chimeneas altas, (Diagnostic and pronostic methods for forecasting atmospheric pollution episodes), $\mathrm{PhD}$ thesis, Escuela técnica superior de ingenieros industriales y de ingenieros de telecomunicación, University of Basque Country (Spain), 1985.

Alonso, L., Millán, M., Albizuri, A., and Navazo, M.: Dispersión de contaminates en la atmósfera II. Chimeneas altas, (Atmospheric pollutant dispersion II. Tall Chimneys), Energía, mayojunio, Madrid (Spain), 101-116, 1987.

Alonso, L., Navazo, M., García, J. A., Gutierrez-Cañas, C., Ilardia, J. L., and Gangoiti, G.: Experimental determination of $\sigma_{y}$, $\sigma_{z}$ and plume rise from a tall stack in the western mediterranean coast (Castellón-Spain), Proceeding of the sixth European symposium, Physico-chemical behaviour of atmospheric pollutants, vol. 1. Varese, Published by the European Commission, Report EUR 15609/1 EN, 1993.

Artiñano, B., Pujadas, M., Plaza, J., Terés, J., and Cabal, H.: Characterization of a pollution episode in stagnant conditions in the greater Madrid area, Proceedings of the sixth European Symposium, Physico-Chemical behaviour of atmospheric pollutants, Varese (Italy), October, Report EUR 15609/1 EN, 1993.

ASME (the American Society of Mechanical Engineers): The recommended guide for the prediction of the dispersion of airborne effluents, ASME, 345 East 47 Street, New York, 10 017, 1-85, 1973.

Briggs, A.: Plume rise predictions, in: Lectures on Air Pollution and Environment Impact Analysis, AMS, Boston (USA), 1975.

Brown, R. M., Cohen, L. A., and Smith, M. E.: Diffusion measurements in the 10-100 km range, J. Appl. Meteorol., 11, 3323-334, 1972.

Carras, J. N. and Williams, D. J.: The long-range dispersion of a plume from an isolated point source, Atmos. Environ., 15, 2205$2217,1981$.
Carroll, J. J. and Baskett, R. L.: Dependence of air quality in a remote location on local and mesoscale transports: A case study, J. Appl. Meteorol., 18, 474-486, 1979.

Carvalho, J. C., Anfossi, D., Trini Castelli, S., and Degrazia, G. A.: Application of a model system for the study of transport and diffusion in complex terrain to the TRACT experiment, Atmos. Environ., 36, 1147-1161, 2002.

CityDelta: An intercomparison of long-term model responses to urban-scale emission-reduction scenarios, http://rea.ei.jrc.it/ netshare/thunis/citydelta, 2005.

COST 710: Harmonisation of the pre-processing of meteorological data for atmospheric dispersion models, COST Action 710 - Final report, European Commission, Directorate-General Science, Research and Development, EUR 18195 EN, 1998.

Csanady, G. T.: Turbulent diffusion in the environment, Reidel, Dordrecht, Holland, 1973.

Chung, Y. S., Gallant, A., Fanaki, F., and Millán, M. M.: On the observation of Mount St. Helens Volcanic emissions, AtmosphereOcean, 19(2), 172-178, 1981.

Doran, J. C., Fast, J. D., and Horel, J.: The VTMX 2000 campaign, Bull. Amer. Meteorol. Soc., 83, 537-551, 2002.

Dudhia, J.: A nonhydrostatic version of the Penn State/NCAR mesoscale model: Validation tests and simulation of an Atlantic cyclone and cold front, Mon. Wea. Rev., 121, 1493-1513, 1993.

Eastman, J. L., Pielke, R. A., and Lyons, W. A.: Comparison of lake-breeze model simulations with tracer data. J. Appl. Meteorol., 34, 1398-1418, 1995.

ENDESA and Martínez, C.: Razón y controversia sobre la Central Térmica Teruel, en Andorra, Gestión Ambiental de Endesa, 167-172, 1994, Also published in Tecno Ambiente, 22 November 1992 .

Fast, J. D. and Darby, L. S.: An evaluation of mesoscale model predictions of down-valley and canyon flows and their consequences using doppler lidar measurements during VTMX 2000, J. Appl. Meteorol., 43, 420-436, 2004.

Fast, J. D.: Mesoscale modeling in areas of highly complex terrain employing a four-dimensional data assimilation technique, J. Appl. Meteorol., 34, 2762-2782, 1995.

Fast, J. D., Lance O'Steen, B., and Addis, R. P.: Advanced atmospheric modeling for emergency response, J. Appl. Meteorol., 34, 626-649, 1995.

Fox, D. G.: Judging air quality model performance, Bulletin American Meteorological Society, 62, 599-609, 1981.

Gangoiti, G., Alonso, L., Maruri, M., Navazo, M., and Pérez-Landa, G.: UHF radar detection and numerical simulation of an episode of Foehn and lee waves over the Northern coast of Iberia, J. Appl. Meteorol., 41, 230-240, 2002.

Grell, G. A., Dudhia, J., and Stauffer, D. R.: A description of the fifth-generation Penn State/NCAR mesoscale model (MM5), NCAR/TN-398+STR, National Center for Atmospheric Research, Boulder, CO (USA), 138, 1995.

Guillot, P., Bonometti, G., Hasenjaeger, H., Van der Meulen, A., Hamilton, P. M., Haulet, R., Laurent, J., Sandroni, S., Cerutti, C., Giovanelli, G., Tirabassi, T., Vittori, O., and Piccinini, P.: First European Community campaign for remote sensing of atmospheric pollution, Lacq (France), 7-11 July 1975, Atmos. Environ., 13, 895-917, 1979.

Hoff, R. H. and Gallant, A. G.: The use of an available SO2 tracer during the 1983 CAPTEX experiment, Atmos. Environ., 
19, 1573-1575, 1985.

Hoff, R. M., Trivett, N. B. A., Millán, M. M., Fellin, P., Anlauf, K. G., and Wiebe, H. A.: The Nanticoke shoreline diffusion experiment, June 1978-III. Ground-based air quality measurements, Atmos. Environ., 16(3), 439-454, 1982.

Huggins, A. W., Koracin, D., Podnar, D., and Xiao, M.: A case study of mesoscale and plume dispersion modeling for a February 2004 cloud seeding event in the Walker river basin of California/Nevada, Proceedings of the 85th AMS annual meeting: 16th Conference on planned and inadvertent weather modification, San Diego, CA, USA, January, 2005.

Hurley, P. and Physick, W.: A lagrangian particle model of fumigation by breakdown of the nocturnal inversion. Atmos. Environ., 25A(7), 1313-1325, 1991.

Kain, J. S. and Fritsch, J. M.: Convective parameterization for mesoscale models: The Kain-Fritsch scheme. The Representation of Cumulus Convection in Numerical Models, Meteor. Monogr., No. 46, Amer. Meteorol. Soc., 165-170, 1993.

Kalnay, E., Kanamitsu, M., Kistler, R., Collins, W., Deaven, D., Gandin, L., Iredell, M., Saha, S., White, G., Woollen, J., Zhu, Y., Chelliah, M., Ebisuzaki, W., Higgins, W., Janowiak, J., Mo, K. C., Roelewski, C., Wang, J., Leetmaa, A., Reynolds, R., Jenne, R., and Joseph, D.: The NCEP/NCAR 40-year re-analysis project, Bull. Amer. Meteorol. Soc., 77, 437-471, 1996.

Kitada, T., Okamura, K., and Tanaka, S.: Effects of topography and urbanization on local winds and thermal environment in the Nohbi Plain, coastal region of central Japan: A numerical analysis by mesoscale meteorological model with $\kappa-\varepsilon$ turbulence model, J. Appl. Meterol., 37(10, part 1), 1026-1046, 1998.

Liu, M. and Carroll, J. J.: A high-resolution air pollution model for dispersive studies in complex terrain, Mon. Wea. Rev., 124(10), 2396-2409, 1996.

Luhar, A. K. and Young, S. A.: Dispersion moments of fumigating plumes-LIDAR estimates and pdf model simulations, BoundaryLayer Meteorol., 104(3), 411-444, 2002.

Luhar, A. K.: The influence of vertical wind direction shear on dispersion in the convective boundary layer, and its incorporation in coastal fumigation models, Boundary-Layer Meteorol., 102, $1-38,2002$.

Martín, F., Palacios, M., and Crespí, S. N.: Simulations of mesoscale circulations in the center of the Iberian Peninsula for thermal low pressure conditions, Part II: Air-parcel transport patterns, J. Appl. Meteorol., 40, 905-914, 2001.

McNider, R. T., Moran, M. D., and Pielke, R. A.: Influence of diurnal and inertial boundary-layer oscillations on long-range dispersion, Atmos. Environ., 22(11), 2445-2462, 1988.

Millán, M. M., Artiñano, B., Alonso, L., Navazo, M., and Castro, M.: The effect of meso-scale flows on regional and long-range atmospheric transport in the western Mediterranean area, Atmos. Environ., 25A, 949-963, 1991.

Millán, M. M. and Chung, Y.-S.: Detection of a plume $400 \mathrm{Km}$ from the source, Atmos. Environ., 11, 937-944, 1977.

Millán, M. M., Artiñano, B., Alonso, L., Castro, M., FernandezPatier, R., and Goberna, J.: Meso-Meteorological Cycles of Air Pollution in the Iberian Penisula, (MECAPIP) (Air Pollution Research Report 44, EUR No. 14834), European Commision DG XII/E-1, Rue de la Loi, 200, B-140, Brussels, 1992.

Millán, M. M., Gallant, A. J., and Turner, H. E.: The application of correlation spectroscopy to the study of dispersion from tall stacks, Atmos. Environ., 10, 499-511, 1976.

Millán, M. M., Otamendi, E., Alonso, L., and Ureta, I.: Experimental characterization of atmospheric diffusion in complex terrain with land-sea interactions, JAPCA, 37(7), 807-811, 1987.

Millán, M. M.: Ozone dynamics in the Mediterranean basin, A collection of scientific papers resulting from the MECAPIP, RECAPMA and SECAP Projects, Air Pollut. Res. Report 78 DGXII, EC, Brussels, 2002.

Millán, M. M.: Passive remote sensing of $\mathrm{SO}_{2}$, Proceedings from the EPA seminar - Workshop on prolonged elevated pollution episodes (PEPE), 19-23 March, 406-424, 1979.

Millán, M. M.: Recent advances in correlation spectroscopy for the remote sensing of $\mathrm{SO}_{2}$, in: Proceedings of the 4th Joint Conference on Sensing of Environmental Pollutants, sponsored by the American Chemical Society, edited by: John Wiley \& Sons, New York, 1978a.

Millán, M. M.: Remote sensing of $\mathrm{SO}_{2}$, a data processing methodology, Proceeding from 4th Joint Conference on Sensing of Environmental Pollutants, American Chemical Society, 1978b.

Millán, M. M.: The regional transport of tall stack plumes, in: Regional and Long-range Transport of Air Pollution, edited by: Sandroni, S., Elsevier Science Publishers, Amsterdam, The Netherlands, 249-280, 1987.

Moran, M. D.: Basic aspects of mesoscale atmospheric dispersion, Chapter 2 in: Mesoscale atmospheric dispersion, edited by: Boybeyi, Z., WIT Press, Great Britain, 424, 2000.

Newcomb, G. S. and Millán, M. M.: Theory, applications, and results of the long-line correlation spectrometer, IEEE Transactions on Geoscience Electronics, GE-8 (3), 149-157, 1970.

Palau, J. L., Mantilla, E., and Millán, M. M.: Estimation of the dispersion of an elevated plume on complex terrain under stable-toneutral conditions, A changing atmosphere: 8th European Symposium on the Physico-Chemical Behaviour of Atmospheric Pollutants, 17-20 September, Torino (Italy), 2001.

Palau, J. L., Pérez-Landa, G., Diéguez, J. J., Monter, C., and Millán, M. M.: The importance of meteorological scales to forecast air pollution scenarios on coastal complex terrain, Atmos. Chem. Phys., 5, 2771-2785, 2005.

Palau, J. L., Pérez-Landa, G., Meliá, J., Segarra, D., and Millán, M. M.: A study of the dispersion of a power plant on complex terrain under winter conditions in the Iberian Peninsula, Fourth Annual Meeting of the European Meteorological Society, EMS Annual meeting Abstracts, vol. I, 00389, Nice (France), 2004.

Palau, J. L.: Dispersión atmosférica de las emisiones de una chimenea alta en terreno complejo (Atmospheric dispersion of a tallstack plume on complex terrain), PhD thesis (in Spanish), University of Valencia (Spain), edited by: CEAM Foundation, 1366, 2003.

Pooler Jr., F. and Niemeyer, L. E.: Dispersion from tall stacks: an evaluation, Proceedings, 2nd International Air Congress (Englund and Beery, editors), Academic Press, New York, 1971.

Portelli, R. V., Kerman, B. R., Mickle, R. E., Trivett, N. B., Hoff, R. M., Millán, M. M., Fellin, P., Anlauf, K. S., Wiebe, H. A., Misra, P. K., Bell, R., and Melo, O.: The Nanticoke shoreline diffusion experiment, June 1978, Atmos. Environ., 16, 413-466, 1982.

Querol, X., Alastuey, A., Lopez-Soler, A., Plana, F., Puicercus, J. A., Mantilla, E., and Palau, J. L.: Daily evolution of sulphate aerosols in a rural area, northeastern Spain - elucidation of an atmospheric reservoir effect, Environ. Poll., 105, 397-407, 1999. 
Salvador, R.: Análisis y modelización de los procesos atmosféricos durante condiciones de brisa en la costa mediterránea occidental: zona de Castellón, (Analysis and modelization of atmospheric processes under sea-breeze conditions at the Eastern Mediterranean coast: Castellon area), $\mathrm{PhD}$ thesis, Universitat Politècnica de Catalunya, Barcelona (Spain), 1999.

Sawford, B. L., Luhar, A. K., Hacker, J. M., Young, S. A., Yoon, I.H., Noonan, J. A., Carras, J. N., Williams, D. J., and Rayner, K. N.: The Kwinana Coastal Fumigation Study: I-Program overview, experimental design and selected results, Boundary Layer Meteorol., 89, 359-384, 1998.

Scorer, R. S.: Dynamics of meteorology and climate, edited by: John Wiley \& Sons, and Praxis publishing, UK, 1997.

Seaman, N. L.: Meteorological Modelling for Air-Quality Assessments, Atmos. Environ., 34, 2231-2259, 2000.

Singer, I. A. and Smith, M. E.: Atmospheric dispersion at Brookhaven National Laboratory, Int. J. Air Water Pollut., 10, 125-135, 1966.

Slade, D. H. (Ed.): Meteorology and atomic energy 1968, Report TID-24190, NTIS, Springfield, Virginia, USA, 445, 1968.

Souto, M. J., Souto, J. A., Pérez-Muñuzuri, V., Casares, J. J., and Bermúdez, J. L.: A comparison of operational Lagrangian particle and adaptive puff models for plume dispersion forecasting, Atmos. Environ., 35, 2349-2360, 2001.

Stauffer, D. R. and Seaman, N. L.: Multiscale four-dimensional data assimilation, J. Appl. Meteorol., 33, 416-434, 1994.

Stohl, A. and Seibert, P.: The FLEXPART particle dispersion model, User Guide, http://www.forst.uni-muenchen.de/EXT/ LST/METEO/stohl/, 2001.
Stohl, A. and Thomson, D. J.: A density correction for lagrangian particle dispersion models, Boundary-Layer Meteorol., 90, 155167, 1999.

Stohl, A., Forster, C., Frank, A., Seibert, P., and Wotawa, G.: Technical note: The Lagrangian particle dispersion model FLEXPART version 6.2, Atmos. Chem. Phys., 5, 2461-2474, 2005.

Stohl, A.: The FLEXPART Particle dispersion model. Version 3.1., http://www.forst.uni-muenchen.de/EXT/LST/METEO/stohl/, 1999.

Uliasz, M.: Lagrangian particle modeling in mesoscale applications, Environmental Modeling II, edited by: Zannetti, P., Computational Mechanics Publications, 71-102, 1994.

Uthe, E. E. and Wilson, W. E.: Lidar observations of the density and behaviour of the Labadie power plant plume, Atmos. Environ., 13, 1395-1412, 1979.

Weil, J. C., Sykes, R. I., and Venkatram, A.: Evaluating air-quality models: Review and outlook, J. Appl. Meteorol., 31, 1121-1145, 1992.

Willmott, C. J.: On the validation of models, Physical Geography, 2(2), 184-194, 1981.

Zaremba, L. L. and Carroll, J. J.: Summer wind flow regimes over the Sacramento valley, J. Appl. Meteorol., 38, 1463-1473, 1999.

Zhang, D. and Anthes, R. A.: A high-resolution model of the planetary boundary layer - Sensitivity tests and comparisons with SESAME-79 data, J. Appl. Meteorol., 21, 1594-1609, 1982. 